\title{
A stochastic multiaxial fatigue model for off- axis cracking in FRP laminates
}

\author{
J.A. Glud ${ }^{1}$, J.M. Dulieu-Barton ${ }^{1,2}$, O.T. Thomsen ${ }^{1,2}$ and L.C.T. Overgaard ${ }^{1}$ \\ ${ }^{1}$ Department of Mechanical and Manufacturing Engineering, Aalborg University \\ Fibigerstraede 16, 9220, Aalborg Oest, Denmark \\ Email: \{jag,ott,lcto\}@m-tech.aau.dk, web page: www.m-tech.aau.dk \\ ${ }^{2}$ Faculty of Engineering and the Environment, University of Southampton \\ Highfield, SO17 1BJ, Southampton, United Kingdom \\ Email: \{janice,o.thomsen\}@soton.ac.uk,web page: www.southampton.ac.uk/engineering
}

Keywords: Fatigue, Polymer-matrix composites, Transverse cracking, Damage mechanics

\begin{abstract}
A model to predict off-axis crack evolution in multidirectional laminates subjected to multiaxial loading is proposed. The model applies multi-scale stress and local fracture mechanics analyses to distinguish between two microscopic damage mechanisms, which govern the damage evolution, as well as determining the magnitude of the damage evolution rate associated with each microscopic damage mechanism. The multi-scale analysis is based on the GLOBLOC off-axis crack damage model, which is extended to include substantial new capabilities such as the influence of crack face sliding interaction and prediction of variations in the stress field due to the local crack density. The extension of the GLOB-LOC model introduces physically based multiaxial fatigue criteria for off-axis crack initiation and mixed-mode off-axis crack propagation. The extended GLOB-LOC model is implemented and it is demonstrated that good predictions are obtained for the damage evolution under various multiaxial stress conditions. Furthermore it is shown that the model only requires input from two different multiaxial stress states to obtain the material parameters for a given FRP ply.
\end{abstract}

\section{Introduction}

Multiaxial fatigue loading is a common loading scenario for many composite structures. It is therefore of great interest to model the influence of such loading scenarios on the fatigue performance of composite materials, to enable reliable and efficient designs and such that shorter time-to-market of composite products can be achieved. Fatigue damage evolution in composite laminates is a complex process because it involves different interacting damage 
Glud, J.A., Dulieu-Barton, J.M., Thomsen, O.T. and Overgaard, L.C.T., "A stochastic multiaxial fatigue model for off-axis cracking in FRP laminates", International Journal of Fatigue, 103, 2017, 576-590. https://doi.org/10.1016/j.ijfatigue.2017.06.012

mechanisms such as off-axis cracking, delamination, crack coupling and fibre breakage [1]. Off-axis cracking is of particular interest as it explains the majority of the stiffness loss observed in composite laminates as they fatigue. The stiffness loss leads to an increase of stress in the load carrying fibres, which promotes fibre failure and may lead to overall structural failure. Accordingly, the development of accurate multiaxial fatigue models for off-axis crack evolution is a key enabler for the prediction of the fatigue life of composite laminates. However, even though off-axis cracking in composite laminates represents an important damage mode for the entire damage evolution process, it has only been given limited attention in the current literature on fatigue models for composite laminates.

According to [2], the fatigue models for composite laminates can be divided into three groups: fatigue life models, residual stiffness/strength models and mechanistic models. Fatigue life models predict failure based on empirical relations and do not model the gradual degradation of the material, which results from the complicated damage evolution in the composite laminates. A recent extensive review of the predictive capabilities of multiaxial fatigue life models can be found in [3], which concludes that all tested models fall short in providing safe and reliable predictions, and highlights the need for physically based models. The residual stiffness/strength models, e.g. [4,5], predict the gradual deterioration of the macroscopic stiffness and/or strength properties, but the proposed evolution laws do not directly relate to physical damage modes in the composite material. Also, considering the highly complex fatigue damage evolution process progressing at different length scales, see e.g. [6], it is questionable that the residual strength/stiffness models provide meaningful results, other than for the laminates that were tested to develop the model, because the models are largely of a phenomenological and empirical nature. The mechanistic models differ from the above models by attempting to provide a physically based model of the actual damage mechanisms within the composite material. Mechanistic models can be divided into two groups; models predicting damage growth and models predicting residual mechanical properties. Several models predicting residual mechanical properties have been proposed. The field of progressive continuum damage models has had many contributions in the past two decades, e.g. [7-10]. Progressive continuum damage models are generally based on the use of an explicit simulation method to model the progression of damage in each ply based on stresses obtained at the mesoscale. The models show good predictive capabilities but require extensive experimental characterisation on unidirectional (UD) and multidirectional (MD) laminates to calibrate empirical constants, which questions their general applicability. Additionally, considering that the fatigue damage evolution occurs at different length scales [6], ranging from the microscopic level at the fibre-matrix interface to the macroscopic scale, it is unclear if the stresses defined on the mesoscale can provide sufficient information to describe the actual damage evolution. This is highlighted in [11] where off-axis crack growth rates were found to depend on both the stress level and the thickness of the cracked layer.

A potential approach to the development of more accurate and generally applicable fatigue models is to develop mechanistic models, which predict the actual damage growth and relate this damage growth to the residual mechanical properties. This would enable fatigue life predictions that are relevant at the structural scale. Mechanistic modelling of the full damage evolution process would be an extremely complex task since it would require modelling 
Glud, J.A., Dulieu-Barton, J.M., Thomsen, O.T. and Overgaard, L.C.T., "A stochastic multiaxial fatigue model for off-axis cracking in FRP laminates", International Journal of Fatigue, 103, 2017, 576-590. https://doi.org/10.1016/j.ijfatigue.2017.06.012

of e.g. off-axis cracking, crack-coupling, delamination and fibre failure. However, since off-axis cracking usually is the first damage mode to occur [11-14], and since it explains the majority of the stiffness loss of composite laminates exposed to fatigue loading, it is clear that the development of predictive models for off-axis crack evolution is a prerequisite for the development of both improved fatigue models and full mechanistic modelling. In addition, such off-axis fatigue models may also be of significant interest for fatigue problems where the residual laminate stiffness is a fundamental design driver as is the case for many practical applications.

Several damage models exist, which can predict the stiffness degradation of composite laminates solely from the volume density of off-axis cracks [15]. Furthermore, some of the models can also provide essential information for damage evolution such as the variation in stress field in the cracked layer and the Crack Face Displacements (CFD), which can be used to compute the Energy Release Rate (ERR) in the off-axis crack front [11]. However, neither of the models refenced in [15] can predict how the off-axis cracking develops when the laminates are subjected to service loads.

Models for predicting the off-axis crack evolution under quasi-static loading have been reported in [16-18]. The offaxis crack growth is unstable when considering quasi-static loading conditions. This means that as soon as an off-axis crack has initiated it will grow unstably until it meets a region with lower stress, e.g. for coupon test specimens this region would be the specimen free edge. This means that the off-axis crack evolution for quasi-static loading can be modelled by using a 2-dimensional (2D) approach, as only the length perpendicular to the off-axis cracks and the thickness of the representative volume element (RVE) in the damaged layer is of importance.

The off-axis crack evolution process for laminates subjected to fatigue loading can be described by initiation of off-axis cracks followed by steady state crack growth $[11,19,20]$. Therefore, the nature of the problem includes full 3D complexity, since the cracks that are initiated can no longer be assumed to span the entire region of uniform stress. To the knowledge of the authors, the only available off-axis crack evolution models for fatigue loading are found in [2125]. The model in [21] predicts the crack density evolution in a cross-ply laminate using Monte-Carlo simulation of distributions of fatigue strength. The model predictions were in good agreement with experiments, but the model is only valid for cross ply laminates and the crack propagation phase was not considered. In the model presented in [22] it was assumed, that the off-axis crack evolution can be described solely from the initiation strength. The model showed good predictive capabilities, but it was found to over predict crack density if a fatigue threshold limit was not introduced. However, in [26] ultra high-cycle fatigue tests on GFRP were carried out and a fatigue threshold limit was not found after $10^{8}$ cycles. As in [21,22], the model presented in [24] neglects the propagation phase, hence the crack density evolution is based on only the initiation strength. The model proposed in [23] takes into account both initiation and the steady state crack growth phase. However, the model relies on a Monte-Carlo type simulation where stochastic parameters are obtained using inverse modelling. The growth of individual cracks originating at the edges and the interaction of the cracks are modelled as the number of cycles is increased. A recent publication [25], presents an improved version of the model described in [23], where the requirement for the cracks to initiate at the edges is removed. However, as in [23] the model still relies on a Monte-Carlo simulation, which means that several 
Glud, J.A., Dulieu-Barton, J.M., Thomsen, O.T. and Overgaard, L.C.T., "A stochastic multiaxial fatigue model for off-axis cracking in FRP laminates", International Journal of Fatigue, 103, 2017, 576-590. https://doi.org/10.1016/j.ijfatigue.2017.06.012

damage variables for initiation and several damage variables describing the crack field must be included in each representative volume element (RVE). Thus rendering the model [25] computationally cumbersome, alongside its improved predictive capabilities.

In view of the above there is a clear need for a computationally efficient multiaxial fatigue model, which is proposed in the present paper by adopting a simplifying parameterisation of the crack evolution process. Hence, here the capability of the well-developed GLOB-LOC off-axis crack damage modelling framework [17,27-29] is extended by the addition of a multiaxial fatigue evolution module. Furthermore a parametric FE-analysis is included in the GLOB-LOC framework to account for the influence of Crack Sliding Displacement (CSD) interaction. Hence, the new modelling framework is capable of predicting variations in the stress field based on the volume average stresses and the local crack density. Thereby providing the information required to determine the type of failure mechanisms that is active, and also the magnitude of the damage evolution rate at the appropriate length scales. The modified model incorporates damage based multiaxial off-axis crack initiation and crack growth criteria (presented in Section 2 of the paper). Following the classification of [2], the model can be categorized as belonging to the group of mechanistic models, as it can predict both damage growth and residual mechanical properties in the form of the stiffness degradation of multiaxial composite laminates.

\section{Fatigue models for off-axis cracks}

A part of the off-axis crack evolution process, defined by initiation and propagation of off-axis cracks, can be considered as deterministic, and, due to the nature of the composite material, part of the process can be considered as stochastic. The influence of mechanical loading on the initiation and propagation of off-axis cracks shows a deterministic dependence on the stress amplitude [12], multiaxial stress state [12], load ratio [30], stacking sequence [11] and the number of load reversals (cycles). Furthermore, the stacking sequence influences the crack growth, because the stacking sequence determines the mode-mixity ( $M M)$ and the magnitude of the total Energy Release Rate (ERR) of the off-axis crack front.

The relationship between an applied stress with constant amplitude and stress ratio, and the number of cycles until an initial flaw initiates into an off-axis crack can be described by a power law relationship, i.e. $\sigma_{\text {fat }}=\sigma_{0}\left(N_{\text {fat }}\right)^{m}$, where $\sigma_{0}$ and $m$ are empirical constants derived from fatigue tests (usually at $50 \%$ survival rate), $N_{\text {fat }}$ is the number of cycles to failure, and $\sigma_{f a t}$ is the equivalent stress range at which the off-axis crack initiates, e.g. [12,31,32].

The crack growth rate (CGR) of an isolated off-axis crack growing in a steady-state manner as function of the maximum ERR for a constant load ratio can be modelled deterministically by adopting the Paris' Law relationship $C G R=D G^{n}[11,12,20,33,34],(C G R$ is also routinely refered to as $\mathrm{da} / \mathrm{dN}), G$ represents the ERR and $D$ and $n$ are empirical constants obtained from fitting Paris' Law to crack growth experimental data.

To account for the influence of multiaxial loading a model based on the two distinct observed damage mechanisms at the micro-scale, i.e. micro-cracks parallel to the fibres and shear cusps was proposed in [35]. The model in [35] 
predicts the type of failure mechanism and the damage evolution rate for each of the damage modes based on two different reference stresses, namely the local hydrostatic tension stress $\left(\sigma^{L H S}\right)$ for micro-cracks parallel to the fibres and the local maximum principal stress $\left(\sigma^{L M P S}\right)$ for shear cusps. The two reference stresses are computed using a fibre-matrix unit-cell model, and the fatigue strengths for damage initiation are determined from two different multiaxial fatigue stress conditions for each damage mode. Recently, an extension to the model in [35] was presented in [36] and this extended model includes the influence of varying stress ratio on off-axis crack initiation.

In [37] a mixed-mode model for off-axis crack propagation is proposed, which was inspired by the initiation model presented in [35], and based on the damage modes observed at the micro-scale in front of a propagating off-axis crack as reported in [38]. A brief description of the mixed-mode model [37] is included in Appendix A of this paper. The mixed-mode model proposed in [37] can be evaluated in an efficient manner using GLOB-LOC, as demonstrated in Section 4 of the present paper. The extended model requires experimental determination of material parameters for Paris' Law derived for two different mixed-mode loading conditions for the considered laminate. Each relationship corresponds to a specific propagation damage mode at the micro-scale either dominated by Mode-I (micro-cracks parallel to the fibres ahead of the crack tip) or Mode-Il fatigue loading (shear cusps ahead of the crack tip). As will be demonstrated in Section 5, the material parameters required for both the initiation and propagation models from [35] and [37], respectively, can be determined using the same laminates and uniaxial fatigue tests. Consequently, the model requires inputs from fatigue tests on only two laminates to efficiently model the influence of multiaxial stress states.

Stress-ratio effects on the off-axis crack evolution has been reported in $[20,23,30]$. Based on the reported results, it was proposed in [23] to use the empirical normalisation principle found in [39] to model the stress-ratio effect on offaxis crack initiation as follows:

$$
\psi^{d}=\frac{\left(1-R_{s}^{d}\right) \sigma_{\max }^{d}}{2 \sigma_{q}^{d}-\left(1+R_{s}^{d}\right) \sigma_{\max }^{d}}
$$

where, $d=$ LHS or LMPS, $\psi^{d}$ are the empirically normalised stress measures, $\sigma_{\max }^{d}$ is the maximum equivalent fatigue reference stress, $\sigma_{q}^{d}$ is the static reference strength and the reference stress ratio is defined as $R_{s}^{d}=\frac{\sigma_{\min }^{d}}{\sigma_{\max }^{d}}$ for each unique damage mode $d$. The empirically normalised S-N curve is therefore given as:

$$
\psi^{d}=\psi_{0}^{d} \cdot\left(N_{\text {fat }}\right)^{m^{d}}
$$

where $d=$ LHS or LMPS, $\psi_{0}^{d}$ and $m^{d}$ are the empirical constants fitted to the normalised S-N data.

It was proposed in [37] to use the same empirical normalisation in terms of equivalent ERR for the influence of varying the stress-ratio on the crack propagation:

$$
\varphi^{\mathrm{d}}=\frac{\left(1-R_{c}^{d}\right) \sqrt{G_{\max }^{d}}}{2 \sqrt{G_{q}^{d}}-\left(1+R_{c}^{d}\right) \sqrt{G_{\max }^{d}}}
$$


where $d=$ LHS or LMPS, $G_{\text {max }}^{d}$ is the maximum equivalent ERR for the active damage mode that drives the crack propagation. $G_{q}^{d}$ is equivalent to the ERR required for unstable crack propagation for each damage mode, and the reference stress ratio $R_{c}^{d}=\frac{\sqrt{G_{\text {min }}^{d}}}{\sqrt{G_{\text {max }}^{d}}}$ for each unique damage mode $d$. Thus, the empirically normalised Paris' Law can be expressed as:

$$
\operatorname{CGR}^{\mathrm{d}}=\varphi_{0}^{\mathrm{d}} \cdot\left(\varphi^{\mathrm{d}}\right)^{n d}
$$

where $d=$ LHS or LMPS, $\varphi_{0}^{\mathrm{d}}$ and $n^{d}$ are the empirical constants fitted to the normalised crack growth data.

Consequently, to account for the stress-ratio effect in the models, it is necessary to test the two laminates under both quasi-static and fatigue loading. It should be noted that the normalisation in Eq. (1) has only been validated for $R_{S}^{d}>0$, and the normalisation in Eq. (3) has only been validated for conditions where the crack faces remain stress free during the entire loading cycle. The normalisations in Eqs. (1) and (3) have not been tested for other loading histories due to the lack of, or very limited, experimental data for compression-tension and compression-compression loading for off-axis crack initiation and propagation.

In addition to the deterministic aspects of the off-axis crack evolution process, as described above, the evolution process also is highly stochastic due to the variable nature of the composite material. The underlying micro material architecture in the form of fibre-bridging, voids, varying fibre-volume fraction and varying layer thickness etc. results in significant levels of scatter of the material data points derived from fatigue tests [20]. In [20] the Weibull distribution was found to model both the stochastic nature of the crack initiation the and crack growth rates well, and provided a means for determining the stochastic material parameters. Furthermore, it was shown that crack initiation and crack growth are not represented by a single S-N and Paris' Law master curve, but instead by S-N and crack growth Weibull fields.

\section{Stochastic model to predict crack density evolution}

The overall aim of the proposed model is to predict the off-axis crack density given as [20]:

$$
\rho=\frac{\sum_{i=1}^{n_{c}} L^{i}}{A_{\text {rve }}}
$$

where $n_{c}$ denotes the number of cracks, $L^{i}$ is the length of the ith crack, and $A_{\text {rve }}$ is the area of the representative volume element [40]. The number of $\operatorname{cracks} n_{c}$ and the length of each crack $L^{i}$ are dependent on the deterministic aspects of the fatigue evolution process as described in section 2, but they are also influenced by the aforementioned stochastic nature of the problem. Therefore, to create a physically based multiaxial off-axis crack evolution model, and to predict the crack density as given in Eq. (5), it is necessary to include and combine the stochastic and the deterministic aspects of the process. 
The probabilistic fatigue strength $\sigma_{f a t}$ is substituted by a Weibull field with the probability of crack initiation $\left(P_{f}\right)$ for the LHS and LMPS initiation damage modes given as:

$$
P_{f}^{d}\left(N_{f a t}^{d}, \sigma_{\text {max }}^{d}, \sigma_{\text {min }}^{d}\right)=1-\exp \left(-\left[\frac{N_{f a t}^{d}}{\left(\frac{\psi^{d}}{\psi_{0}^{d}}\right)^{\frac{1}{m^{d}}}}\right]^{\beta_{s}^{d}}\right)
$$

where $d=$ LHS or LMPS, the model input is the number of cycles to fatigue failure $N_{f a t}^{d}$, and the loading state is given by $\sigma_{\max }^{d}$ and $\sigma_{\min }^{d} . \psi_{0}^{d}$ and $m^{d}$ are fitting parameters for the normalised S-N power law relationship given in Eq. (2), and $\beta_{s}^{d}$ is the Weibull shape parameters for the LHS and LMPS damage modes.

The probabilistic fatigue strength functions for the two damage modes $P_{f}^{d}\left(N_{f a t}^{d}, \sigma_{\max }^{d}, \sigma_{\min }^{d}\right)$ are identical, but they each have $\sigma_{q}^{d}, \Psi_{0}^{d}, m^{d}, \beta_{s}^{d}$ as separate material parameters. It is important to note that $\sigma_{\max }^{d}$ and $\sigma_{\min }^{d}$ should be evaluated using the multiscale approach proposed in [35].

The probabilistic crack growth CGR field, $P_{c}^{d}$, for the LHS and LMPS propagation modes are given as:

$$
P_{c}^{d}\left(C G R^{d}, G_{\text {max }}^{d}, G_{\min }^{d}\right)=1-\exp \left(-\left[\frac{C G R^{d}}{\varphi_{0}^{d}\left(\varphi^{\mathrm{d}}\right)^{n^{d}}}\right]^{\beta_{c}^{d}}\right)
$$

$d=$ LHS or LMPS, $C G R^{d}$ is the crack growth rate for a particular damage mode at the maximum ERR loading, $\varphi_{0}^{d}$ and $n^{d}$ are fitting parameters for the Paris' Law relationship given by Eq. (4), and $\beta_{c}^{d}$ is the Weibull shape parameter for the LHS and LMPS initiation and propagation damage modes, respectively.

The crack growth field for the LHS and LMPS damage modes $P_{c}^{d}\left(C G R^{d}, G_{\max }^{d}, G_{\min }^{d}\right)$ are identical, but they each have $G_{q}^{d}, \varphi_{0}^{d}, n^{d}$ and $\beta_{c}^{d}$ as separate material parameters. It should be noted that $G_{\max }^{d}$ and $G_{\min }^{d}$ should be evaluated using a suitable off-axis crack damage model together with the approach presented in [37]. The damage model used in the present work is the GLOB-LOC model described in [17], with additional modifications as described in Section 4.

The off-axis crack evolution process can be described by the initiation of off-axis cracks at the micro-scale and the crack propagation at the meso-scale. The details of the model developed to predict the crack evolution process is shown in Figure 1. Firstly, information about the laminate, material, RVE and loading history is provided as an input, and then the algorithm starts the explicit simulation. A fatigue block load is applied to the laminate that establishes the stress/strain state in the laminate at the macroscale. The algorithm then loops through the laminate layers and derives the probability of failure initiation at each of the allowable crack initiation locations at the microscale. The total probability of crack initiation can then be calculated at the mesoscale to establish the number of cracks $\left(n_{c}\right)$ in the laminate. The CGR for each initiated crack is then computed and subsequently the crack density in the laminate layer is updated. When the damage in all laminate layers has been computed, the next fatigue step follows and the algorithm stops when it has looped through all fatigue steps provided by the user. The assumptions adopted in each stage of the model and how the different steps are computed are described in detail in the following two subsections. 
Glud, J.A., Dulieu-Barton, J.M., Thomsen, O.T. and Overgaard, L.C.T., "A stochastic multiaxial fatigue model for off-axis cracking in FRP laminates", International Journal of Fatigue, 103, 2017, 576-590. https://doi.org/10.1016/j.ijfatigue.2017.06.012

\section{Initiation:}

An RVE comprising an off-axis layer in a test specimen subject to in-plane stress is shown in Figure 2. Only off-axis cracks initiating from the edges are considered, and this fundamental assumption corresponds well with experimental observations which suggest that initiation at the edges is the predominant mechanism [11,41]. In addition, the maximum crack density is assumed to be $\rho_{\max }=1 / t_{k}$ as assumed in [17], where $t_{k}$ is the layer thickness. This assumption is well justified from experimental results reported in literature, see. e.g. [11,41]. The off-axis layer is therefore divided into $n_{i}=W / t_{k}$ crack elements, where $W$ is shown in Figure 2 . Consequently, each crack element can only have one crack, which also means that the crack only stops when it meets the opposite edge of the cracked element, i.e. for this case at the edge of the test specimen. Therefore only one crack is allowed to initiate at one side or the other and cracks cannot grow together. From a physical point of view this might lead to poor predictions for cases where the crack fields are more complex than is the case for full width cracks. However, it was decided to adopt this simplification to reduce the computational cost, and also to show the applicability of the method in the simplest case for off-axis crack evolution in multiaxially loaded laminate layers. The relation between the $P_{f}$ and the number of cracks initiated is adopted from [17] to predict the number of cracked elements as:

$$
n_{c}=W \rho=W \rho_{\max } P_{f}
$$

where $\rho$ denotes the total crack density, and $P_{f}$ is the total probability of crack initiation given in Eq. (9).

When off-axis cracks initiate sufficiently close to other off-axis cracks there will be interaction and the stress between the cracks is lowered. This creates a shielding effect on new crack formation, which means that $\psi^{\mathrm{d}}$ varies along the edge as soon as a crack is present. For off-axis crack evolution under quasi-static loading it is suggested in [17] to use the average stress in each element to compute the probability of failure. However, due to the nonlinear dependence between the number of cycles to failure and the fatigue stress from the S-N power law, an error may be introduced if the variations in the stress field are not taken into account. To compute the probability of crack initiation, the edge is further divided into initiation-elements $n_{j}=r \cdot W / t_{k}$, where $r$ is the number of crack initiation elements per crack element. In the following derivation it is assumed that a sufficiently fine division of initiation-elements has been chosen, such that the stress state within each element can be treated as constant. The two damage modes LMPS and LHS are assumed to be stochastic independent events, since they represent different damage mechanisms. Therefore the total probability of failure can be evaluated as the product of the respective survival probability considering each damage mode. Moreover, according to the weakest link principle [42], the product of survival probabilities for all crack initiation elements should equal to the survival probability in the full volume defined by Eq. (6). The total survival probability when combining the two different damage modes is therefore given as:

$$
1-P_{f}=\left(1-P_{f}^{L H S}\right) \cdot\left(1-P_{f}^{L M P S}\right)=P_{S}^{L H S} \cdot P_{S}^{L M P S}=\left(\prod_{j=1}^{n_{j}} P_{S}^{L H S(j)}\right) \cdot\left(\prod_{j=1}^{n_{j}} P_{s}^{L M P S(j)}\right)
$$


where $P_{S}^{L H S(j)}$ and $P_{S}^{L M P S(j)}$ are the survival probabilities of the $j$ th crack initiation element for each damage mode. The survival probability of the $j$ th element can be derived from the weakest link principle as described in [42] and is given as:

$$
P_{s}^{d(j)}=\exp \left(-\left[\frac{N_{f a t}}{\delta_{n_{j}}\left(\frac{\psi^{\mathrm{d}}}{\psi_{0}^{d}}\right)^{\frac{1}{m^{d}}}}\right]^{\beta_{s}^{d}}\right)=\exp \left(-\left[\frac{N_{f a t}}{\left(n_{j}\right)^{\beta_{s}^{d}}\left(\frac{\psi^{\mathrm{d}}}{\psi_{0}^{d}}\right)^{\frac{1}{m^{d}}}}\right]^{\beta_{s}^{d}}\right)
$$

The damage measure is therefore the survival probability of each initiation element, which is the same type of damage measure as proposed in [42]. However, the probability given in Eq. (10) cannot be evaluated explicitly, since the stress state may not be constant. This can happen either if the applied load varies or if an off-axis crack has initiated, which will cause a shielding effect, reducing the stress in the neighbourhood of the crack. To overcome this, an explicit method is used to obtain the probability for off-axis crack initiation. When accounting for a varying stress history, the damage accumulation is derived by establishing the equivalent number of cycles for the given stress, followed by evaluation of the new survival probability:

$$
\begin{gathered}
N_{e q}^{d(t)(j)}=\left(-\ln \left(P_{s}^{d(t-1)(j)}\right)\right)^{1 / \beta_{s}} \cdot\left(n_{j}\right)^{\beta_{s}^{d}}\left(\frac{\psi^{\mathrm{d}(\mathrm{t})(j)}}{\psi_{0}^{d}}\right)^{\frac{1}{m^{d}}} \\
P_{S}^{d(t)(j)}=\exp \left(-\left[\frac{N_{e q, j}^{d(t)(j)}+\Delta N^{d(t)}}{\left(n_{j}\right)^{\beta_{s}^{d}}\left(\frac{\Psi^{\mathrm{d}(\mathrm{t})(\mathrm{j})}}{\psi_{0}^{d}}\right)^{\frac{1}{m^{d}}}}\right]^{\beta_{s}^{d}}\right)
\end{gathered}
$$

where $N_{e q}^{d(t)(j)}$ is the equivalent number of cycles at the th load step required to produce the same survival probability at the current stress level $\psi^{\mathrm{d}(\mathrm{t})}$, and $\Delta N^{d(t)}$ is the cycle step applied at the th load step for damage mode $d$.

\section{Propagation:}

The probability of failure does not provide information about where cracks initiate. It is assumed that cracks initiate between already existing cracks because the stress at this location is the highest and the crack growth rate will be the highest as well. The numbering of the elements containing a crack, c, shown in Figure 2 is the order and location of crack initiation and hence provides a conservative estimation of the crack density. Moreover, for computational efficiency the crack initiation is modelled such that the cracks initiate at opposite edges and the length of the cracks is assumed to be ordered as $L_{1}>L_{2}>\cdots>L_{n_{c}}$ (as shown in Figure 2), where the subscript denotes the crack number. This assumption makes it possible to compute the ERR for each crack prior to the simulation, so the entire 3D stress field does not need to be computed. The proportional scalings of the Paris' Law relations defined by Eq. (7) are 
assigned to each element through a Monte-Carlo approach and normalised mode I and mode II ERRs (used to obtain the equivalent ERR's in [37]) are assigned to each crack element before the simulation is started. The normalised ERRs are given as:

$$
\begin{aligned}
& G_{I, i}^{\text {norm }}=\frac{G_{I, i}\left[\rho\left(x_{i}\right)\right]}{\left(\sigma_{22}^{0}\right)^{2}} \\
& G_{I I, i}^{n o r m}=\frac{G_{I I, i}\left[\rho\left(x_{i}\right)\right]}{\left(\tau_{12}^{0}\right)^{2}}
\end{aligned}
$$

where $G_{I, i}\left[\rho\left(x_{i}\right)\right]$ and $G_{I I, i}\left[\rho\left(x_{i}\right)\right]$ is the local ERR, which can be obtained from Eq. (26) and (27) in Section 4, and $\rho\left(x_{i}\right)$ is the local crack density at the $i$ th crack element and is given by $\rho\left(x_{i}\right)=\frac{\left(2^{\left\lfloor\frac{\log (i-1)}{\log (2)}\right\rfloor}\right)}{W}$ for $i>1$, where \lfloor\rfloor denote the floor rounding function.

For each cracked element the crack growth rate is computed based on the Paris' Law mastercurves described in [37]:

$$
C G R_{c}^{d}=\frac{\partial a_{c}^{d}}{\partial N}=\varphi_{0, c M}^{d} \varphi_{0}^{d}\left(\varphi^{\mathrm{d}}\left[G_{I, c}^{n o r m}, G_{I I, c}^{n o r m}, \sigma_{22}^{0}, \tau_{12,}^{0}\right]\right)^{n^{d}} \text { for } c=\left[1: n_{c}\right]
$$

where $\varphi_{0, c M}^{d}$ denotes the assigned proportional scaling obtained for simplicity from the Monte-Carlo approach using Eq. (7). It is also possible to assign $\varphi_{0, c M}^{d}$ deterministically by integrating the experimentally derived Weibull distribution. As demonstrated in [37] the propagation mode (mastercurve) that predicts the fastest CGR should be used to predict the crack growth. Hence the crack growth rate for each propagation mode (LHS and LMPS) in each cracked element is computed, and the highest crack growth rate is used to advance the crack. The new crack length of the cth crack element is:

$$
\begin{gathered}
\left.L_{c}^{t}=\left(L_{c}^{t-1}+\max _{d}\left\{C G R_{c}^{d, t}\right\} \cdot \Delta N^{t}\right) \cdot \mathrm{H}\left\{L^{v}-\left(L_{c}^{t-1}+\max _{d}\left\{C G R_{c}^{d, t}\right\} \cdot \Delta N^{t}\right)\right)\right\}+\left(L^{v}\right) \\
\cdot \mathrm{H}\left\{\left(L_{c}^{t-1}+\max _{d}\left\{C G R_{c}^{d, t}\right\} \cdot \Delta N^{t}\right)-L^{v}\right\} \text { for } c=\left[1: n_{c}\right]
\end{gathered}
$$

where $H($ ) denotes the Heaviside function used to ensure that the crack propagation stops, when the off-axis cracks reach the opposite edge $L^{v}$.

If an off-axis crack has grown so that it has met the other edge, it will change the stress field at this edge as well. The stress field at the edge is therefore computed based on both the initiated cracks at the considered edge and the full width cracks. Finally, the crack density is computed using Eq. (5).

\section{Extension of the GLOB-LOC multi-scale stress analysis}

The off-axis evolution model presented in Section 3 is a multiscale model, and consequently a computational multiscale stress analysis tool must be developed to evaluate the proposed criteria. The multiscale approach adopted in the present work is based on the GLOB-LOC damage modelling framework $[17,27-29]$, which belongs to the class of CFD (Crack Face Displacement) models [15]. In this section the implementation of the GLOB-LOC model is validated and the GLOB-LOC model is extended with additional stress analysis tools required for the off-axis crack evolution 
prediction. The extension and validation of the GLOB-LOC model are accomplished by means of detailed parametric FEA of constrained off-axis cracks. The GLOB-LOC model is based on the micro-mechanical theorem stating that the volume average strains in each layer are equal to boundary-averaged strains. This means that the boundary value strains, and hence the stiffness of the laminate can be computed when the Crack Face Displacements (the CFDs) are known. In $[27,28]$, power law master curves are derived to predict the CFDs based on the thickness and stiffness of the constraining and cracked layers and the stress state in the undamaged laminate. It should be noted that computations of the Crack Sliding Displacement (CSD), the Crack Opening Displacements (COD) and the stress state between cracks are required to evaluate the initiation and propagation criteria outlined in section 3 . For the case of non-interacting off-axis cracks, the COD and CSD are given as:

$$
\begin{aligned}
& C S D=u_{1 a}=\frac{1}{2 t_{k}} \int_{-\frac{t_{k}}{2}}^{\frac{t_{k}}{2}} \Delta u_{x}(z) d z=\frac{t_{k} \tau_{120}^{k}}{G_{12}} u_{1 \text { an }}=\frac{t_{k} \tau_{120}^{k}}{G_{12}}\left(A_{1}+B_{1}\left(\frac{G_{12}}{G_{x y}^{\text {sublam }}}\right)^{n_{1}}\right) \\
& C O D=u_{2 a}=\frac{1}{2 t_{k}} \int_{-\frac{t_{k}}{2}}^{\frac{t_{k}}{2}} \Delta u_{y}(z) d z=\frac{t_{k} \sigma_{220}^{k}}{E_{2}} u_{2 a n}=\frac{t_{k} \sigma_{220}^{k}}{E_{2}}\left(A_{2}+B_{2}\left(\frac{E_{2}}{E_{x}^{\text {sublam }}}\right)^{n_{2}}\right)
\end{aligned}
$$

where $t_{k}$ is the thickness of the cracked layer, and $\Delta u_{x}, \Delta u_{y}$ is the displacement jump across the crack, $\tau_{120}^{k}$ and $\sigma_{220}^{k}$ are the shear and transverse normal stress in the undamaged laminate, $G_{12}$ and $E_{2}$ are the shear modulus and transverse Young's modulus in the cracked layer of the material coordinate system of layer $k, G_{x y}^{\text {sublam }}$ and $E_{x}^{\text {sublam }}$ are the shear modulus and transverse Young's modulus of the constraining laminate in a coordinate system defined by having the YZ-plane aligned with the off-axis crack plane of layer $k . A_{1}, n_{1}, A_{2}$, and $n_{2}$ are empirical constants, and $B_{1}$ and $B_{2}$ are empirical functions of the layer thicknesses. (These constants/functions have been derived from FEanalysis, and the expressions for $A_{1}, B_{1}, n_{1}, A_{2}, B_{2}$ and $n_{2}$ can be found in [17].)

The off-axis cracks will start to interact when they are located close to each other, assumed to be within a distance of 4 layer thicknesses $\left(\sim l=4 t_{k}\right)$. This means that the CSD and the COD become functions of the crack density. The interaction in terms of $C O D$ can be accounted for by introducing an interaction function as described in $[17,29]$. However, the in $[17,29]$ an interaction function for CSD is not proposed. Assuming a similar interaction function for the $C S D$ as proposed for the $C O D$ in [17], and neglecting the influence of friction when the crack surfaces close, the CSD and COD are given as:

$$
\begin{gathered}
\operatorname{CSD}\left(\rho_{k n}\right)=\lambda_{1}\left(\rho_{k n}\right) u_{1 a}=\tanh \left(k_{1} / \rho_{k n}\right) u_{1 a} \text { for } \sigma_{22}>0 \\
\operatorname{COD}\left(\rho_{k n}\right)=\lambda_{2}\left(\rho_{k n}\right) u_{2 a}=\tanh \left(k_{2} / \rho_{k n}\right) u_{2 a}
\end{gathered}
$$

where $k_{1}$ and $k_{2}$ are empirical constants giving the best fit to CSD and COD results obtained from parametric FEanalyses, and $\rho_{k n}$ denotes the normalised crack density given as $\rho_{k n}=t_{k} \rho_{k}$.

Numerical values of $k_{1}$ and $k_{2}$ for the composite materials used in the experimental work described in Table 1 were determined from a 3D FE-analysis (FEA). A sketch of the 3D model is shown in Figure 3(a), and the boundary conditions (B.C.'s) for the study of the COD and the CSD interaction are shown in Figure 3(b) and Figure 3(c), 
respectively. ANSYS 15.0 was used for the FE analyses with 12 SOLID185 elements through the thickness of the plies. The results from the FE analysis are shown in Figure 4 with the COD interaction is in close agreement with [29]. The interaction functions given in Eq. (19) and (20) were fitted to the FE results using $k_{1}=1.3$ and $k_{2}=0.74$, respectively, and it is seen in Figure 4 that these values provide a satisfactory fit for the CSD and COD interaction obtained from FEA.

Since the GLOB-LOC model is based on volume averaging, the varying stress field within a cracked layer between offaxis cracks is not readily obtained. The average stress in a cracked layer can be obtained [17] and is dependent on the $C O D$ and CSD in the cracked layer. Therefore cracked layers are considered separately and laminates are assumed to be symmetric and balanced, so any coupling effects on the COD and CSD values cannot be considered. By using force equilibrium conditions and macroscopic strain compatibility for all laminate layers it can be shown that the average transverse normal stress as function of the COD is given as [43]:

$$
\sigma_{22, a v g}^{k}=k_{\sigma 2} \sigma_{220}^{k}=\left(1-2 u_{2 a n}\left(\rho_{k n}\right) \rho_{k n} \frac{t_{k} t_{s} E_{T}^{S}}{E_{T 0}^{L A M}\left(\frac{t_{k}}{2}+t_{s}\right)}\right) \sigma_{220}^{k}
$$

where $E_{T 0}^{L A M}$ is the initial 'average' modulus of the whole laminate in the undamaged condition, $t_{s}$ is the average thickness of the sub-laminates and $E_{T}^{S}$ is the average Young's modulus of the top and bottom sub-laminate perpendicular to the off-axis crack as defined in [17].

Reference [43] does not provide the derivation of the average shear stress, but using the same assumptions as for the transverse normal stress it can be shown that the average shear stress in a cracked layer is given as:

$$
\tau_{12, \mathrm{avg}}^{k}=k_{\sigma 1} \tau_{120}^{k}=\left(1-2 u_{1 a n}\left(\rho_{k n}\right) \rho_{k n} \frac{t_{k} t_{s} G_{T}^{S}}{G_{T 0}^{L A M}\left(\frac{t_{k}}{2}+t_{s}\right)}\right) \tau_{120}^{k}
$$

where $G_{T}^{S}$ is the average shear-modulus of the top and bottom sub-laminate, and $G_{T 0}^{L A M}$ is the initial 'average' shear modulus of the whole laminate in the undamaged condition.

As described in [44], shear lag models predict the varying stress field between off-axis cracks by solving a second order ordinary differential equation which has a solution given as:

$$
\sigma_{22}^{k}(\xi)=\sigma_{220}^{k}\left(1-\frac{\cosh \left(\Phi_{2} \xi\right)}{\cosh \left(\Phi_{2} \frac{1}{2 \rho_{k n}}\right)}\right)
$$

where $\Phi$ is an unknown constant depending on the laminate properties, $\xi$ is a non-dimensional coordinate given as $\xi=x / t_{k}$, where $x=0$ is the centre position between two off-axis cracks.

The unknown material constant, $\Phi_{2}$, can be determined by solving the following: 


$$
\sigma_{22, a v g}^{k}=k_{\sigma 2} \sigma_{220}^{k}=\frac{\sigma_{220}^{k}}{\rho} \int_{-\frac{1}{2 \rho t_{k}}}^{\frac{1}{2 \rho t_{k}}}\left(1-\frac{\cosh \left(\Phi_{2} \xi\right)}{\cosh \left(\Phi_{2} \frac{1}{2 \rho_{k n}}\right)}\right) d \xi
$$

In a similar manner the shear stress $\tau_{12}^{k}(\xi)$ is also be described by a solution similar to Eq. (23) but will have a different material constant, denoted as $\Phi_{1}$, which is determined by solving:

$$
\tau_{12, a v g}^{k}=k_{\sigma 1} \tau_{120}^{k}=\frac{\tau_{120}^{k}}{\rho} \int_{-\frac{1}{2 \rho t_{k}}}^{\frac{1}{2 \rho t_{k}}}\left(1-\frac{\cosh \left(\Phi_{1} \xi\right)}{\cosh \left(\Phi_{1} \frac{1}{2 \rho_{k n}}\right)}\right) d \xi
$$

A comparison between the stress between off-axis cracks as predicted by the extended GLOB-LOC model using EqS.

(19)-(25) and FE analyses is shown in Figure 5. It is observed that the predictions of the FE analyses and the methodology proposed in this paper compares very well, and is a strong indication that the extended GLOB-LOC model is valid. It should be noted that the stress field obtained from Eqs. (24)-(25) is used to compute LHS and LMPS in the crack initiation elements (10), which in turn relies on the multi-scale model given in [35].

To evaluate Eq. (15), and predict the CGR, it is necessary to obtain the mode I and mode II ERR as follows [11]:

$$
\begin{aligned}
& G_{I}=\frac{1}{2 t_{k}} \sigma_{22} \int_{0}^{t_{k}} \Delta u_{y}(z) d z=\sigma_{22}\left(\rho_{k n}\right) \operatorname{COD}\left(\rho_{k n}\right) \\
& G_{I I}=\frac{1}{2 t_{k}} \tau_{12} \int_{0}^{t_{k}} \Delta u_{x}(z) d z=\tau_{12}\left(\rho_{k n}\right) \operatorname{CSD}\left(\rho_{k n}\right)
\end{aligned}
$$

where $G_{I}$ and $G_{I I}$ denotes the ERR associated with pure mode I and mode II, respectively, $\sigma_{22}$ and $\tau_{12}$ are the transverse normal stress and the shear stresses ahead of the propagating crack front, and COD and CSD are the crack face displacements behind the crack front. $\sigma_{22}$ and $\tau_{12}$ can be obtained from Eq. (24) and (25), and CSD and COD can be obtained from Eq. (19) and (20).

The additional capabilities for the GLOB-LOC model presented in this section allows predictions of the necessary multiscale stress measures required to define damage evolution at the different length scales included in the off-axis crack evolution process. Compared to detailed FEA, the multi-scale stress measures are computationally efficient to evaluate and enable predictions of damage evolution to be made at larger scales.

\section{Material parameter input for extended GLOB-LOC model}

Three laminate plates were produced to provide the empirical constants required in the model. The plates were produced using manual material placement and vacuum assisted resin transfer moulding. The glass fibre was $600 \mathrm{~g} / \mathrm{m}^{2}$ stitched E-glass NCF UD, and an epoxy resin and hardener typical for wind turbine blade applications were used as matrix material. The layups of the three laminate plates were $\left[0^{\circ}\right]_{6},\left[0^{\circ} /-40^{\circ} / 0^{\circ} / 40^{\circ}\right]_{s}$ and $\left[0^{\circ} /-90^{\circ}\right]_{s}$. The $\left[0^{\circ}\right]_{6}$ laminate was used to derive the constitutive properties of the laminate layers, and the $\left[0^{\circ} /-40^{\circ} / 0^{\circ} / 40^{\circ}\right]_{s}$ and $\left[0^{\circ} /-90^{\circ}\right]_{s}$ laminates were used to derive the quasi-static strengths, S-N curves and the Paris' Law like relationships required for 
Glud, J.A., Dulieu-Barton, J.M., Thomsen, O.T. and Overgaard, L.C.T., "A stochastic multiaxial fatigue model for off-axis cracking in FRP laminates", International Journal of Fatigue, 103, 2017, 576-590. https://doi.org/10.1016/j.ijfatigue.2017.06.012

the proposed model. The constitutive properties of the three different laminates are given in Table 1. The fibre volume fractions were measured by means of a burn-off test [20]. It should be noted that the type of stitching used for the tested fabric results in the creation of fibre tows. These fibre tows may have a higher fibre volume fraction than the fibre volume fraction measured in the burn off-test and as argued in [35] such an increase in fibre volume fraction increases the local stress in the matrix and hence the possibility of crack initiation.

\begin{tabular}{|c|c|c|c|c|c|}
\hline \multicolumn{6}{|c|}{ [06] Laminate (No. Specimens tested: 3 in $0^{\circ}, 3$ in $90^{\circ}$ and 1 ARCAN specimen in pure shear) } \\
\hline$E_{1}[\mathrm{GPa}]$ & $E_{2}[\mathrm{GPa}]$ & $v_{12}$ & $G_{12}[\mathrm{GPa}]$ & $V_{f}$ & $\begin{array}{c}\text { Thickness } \\
{[\mathrm{mm}]}\end{array}$ \\
\hline $44.3 \pm 2.5$ & $12.1 \pm 0.23$ & $0.36 \pm 0.02$ & $3.93 \pm 0.09 * *$ & $56 \%$ & $3.07 \pm 0.03$ \\
\hline \multicolumn{6}{|c|}{$[0 / 90]_{s}$ Laminate (No. Specimens tested: 3 in $0^{\circ}$ ) } \\
\hline \multicolumn{3}{|c|}{$E_{x 0}^{l a m}[\mathrm{GPa}]$} & \multicolumn{2}{|c|}{$V_{f}$} & Thickness [mm] \\
\hline \multicolumn{3}{|c|}{$26.2 \pm 0.5$} & \multicolumn{2}{|c|}{$47 \pm 1 \%$} & $2.30 \pm 0.06$ \\
\hline \multicolumn{6}{|c|}{$[0 /-40 / 0 / 40]_{s}$ Laminate (No. Specimens tested: 3 in $0^{\circ}$ ) } \\
\hline \multicolumn{3}{|c|}{$E_{x 0}^{l a m}[\mathrm{GPa}]$} & \multicolumn{2}{|c|}{$V_{f}$} & Thickness [mm] \\
\hline \multicolumn{3}{|c|}{$29.3 \pm 2.2$} & \multicolumn{2}{|c|}{$51 \pm 1 \%$} & $4.34 \pm 0.09$ \\
\hline \multicolumn{3}{|c|}{ E-Glass } & \multicolumn{3}{|c|}{ Epoxy } \\
\hline \multicolumn{2}{|c|}{$E_{f} *[\mathrm{GPa}]$} & $v_{f}^{*}$ & \multicolumn{2}{|c|}{$E_{m} *[\mathrm{GPa}]$} & $v_{m}^{*}$ \\
\hline \multicolumn{2}{|c|}{70} & 0.22 & \multicolumn{2}{|c|}{3.2} & 0.37 \\
\hline
\end{tabular}

Table 1: Constitutive properties for the tested material. *Assumed material properties taken from [35] which are typical for E-glass and epoxy materials. **The strain measurements were obtained using DIC and the scatter band for $G_{12}$ is the 5-95\% confidence interval for the measured shear modulus.

The damage evolution in the quasi-static and fatigue tests was obtained using the ACC technique [40], and a material parameter identification similar to the one presented in [20] was adopted to automatically derive the quasi-static strengths, S-N curves based on initiation of isolated off-axis cracks, and Paris' Law relationships based on crack growth rates obtained for the propagation of isolated crack fronts. The number of fatigue tests carried out for the two laminates is given in Table 2. In addition, four quasi-static loading tests were carried out for each of the $[0 \%$ $\left.40^{\circ} / 0^{\circ} / 40^{\circ}\right]_{s}$ and $\left[0^{\circ} /-90^{\circ}\right]_{s}$ laminates. 


\begin{tabular}{|c|c|c|c|c|}
\hline & \multicolumn{4}{|c|}{$\left[0^{\circ} /-90^{\circ}\right]_{s}$} \\
\hline Load & $\begin{array}{c}N_{x}=302 \\
{[\mathrm{~N} / \mathrm{mm}]}\end{array}$ & $\begin{array}{c}N_{x}=240 \\
{[\mathrm{~N} / \mathrm{mm}]}\end{array}$ & $\begin{array}{c}N_{x}=203 \\
{[\mathrm{~N} / \mathrm{mm}]}\end{array}$ & $\begin{array}{c}N_{x}=160 \\
{[\mathrm{~N} / \mathrm{mm}]}\end{array}$ \\
\hline \multirow[t]{2}{*}{ \# tests } & 4 & 2 & 1 & 1 \\
\hline & \multicolumn{4}{|c|}{$\left[0^{\circ} /-40^{\circ} / 0^{\circ} / 40^{\circ}\right]_{s}$} \\
\hline Load & $\begin{array}{c}N_{x}=1147 \\
{[\mathrm{~N} / \mathrm{mm}]}\end{array}$ & & & $\begin{array}{c}N_{x}=547 \\
{[\mathrm{~N} / \mathrm{mm}]}\end{array}$ \\
\hline \# tests & 2 & & & 2 \\
\hline
\end{tabular}

Table 2: Fatigue tests carried out for each load level for the two laminates.

The S-N data obtained from the experimental campaign along with fitted S-N curves for the LHS and LMPS initiation damage modes can be seen in

Figure 6a. The multiaxial failure envelope $\left(\sigma_{22}, \tau_{12}\right)$ for the tested material predicted by the model from [35] is plotted in

Figure $6 \mathrm{~b}$ for different numbers of loading cycles to failure for the case where $R=0.1$, which represents the stresslevel at which the material calibration tests were carried out. The constant life diagram obtained by using the normalisation defined by Eq. (1) for each damage mode is shown in

Figure 6c.

Figure 7a shows the measured crack growth rates and Paris' Law fits as function of $G_{\max }^{L H S}$ and $G_{\max }^{L M P S}$, and constant CGR curves are plotted in Figure 7b. The model parameters required in Eqs. (6)-(7) have been derived from the fatigue and quasi-static test results and are given in Table 3.

\begin{tabular}{|c|c|c|c|c|c|c|c|c|}
\hline & $m^{d}$ & $\psi_{0}^{d}$ & $\beta_{s}^{d}$ & $\sigma_{t}^{d}[\mathrm{MPa}]$ & $n^{d}$ & $\varphi_{0}^{d}$ & $\beta_{c}^{d}$ & $\begin{array}{c}G_{q}^{d} \\
{\left[\mathrm{~kJ} / \mathrm{m}^{2}\right]}\end{array}$ \\
\hline$d=$ LHS & -0.13 & 0.53 & $1.02_{-0.20}^{+0.25}$ & $148_{-4}^{+4}$ & 7.76 & $10^{3.06}$ & $0.96_{-0.12}^{+0.12}$ & $0.98_{-0.06}^{+0.05}$ \\
\hline$d=$ LMPS & -0.16 & 1.22 & $1.20_{-0.15}^{+0.17}$ & $>194^{*}$ & 3.41 & $10^{-1.86}$ & $0.8_{-0.22}^{+0.22}$ & $1.28^{*}$ \\
\hline
\end{tabular}

Table 3: Quasi-static and fatigue evolution properties derived using ACC [20]. *The quasi-static strength for the LMPS damage mode ([0\%-40\% $\% 40]_{s}$ laminate) could not be obtained, since the specimens suffered from failure close to the tabs before the off-axis cracks initiated. The quasistatic strength has therefore been assigned the stress value at tab-failure. 
Glud, J.A., Dulieu-Barton, J.M., Thomsen, O.T. and Overgaard, L.C.T., "A stochastic multiaxial fatigue model for off-axis cracking in FRP laminates", International Journal of Fatigue, 103, 2017, 576-590. https://doi.org/10.1016/j.ijfatigue.2017.06.012

It should be noted that the measured strength determined in each of the two initiation damage modes represents a lower bound, since only the first non-interacting cracks are included in this measurement. This lower bound is known as the length effect [42] and the measured strength can be corrected using the weakest link approach. This means that the measured normalised strength $\left(\psi_{0}\right)$ therefore has to be corrected as: $\psi_{0, u}=u \psi_{0}$ for the model to provide accurate results. For this work, the correction factor $u$ is determined by scaling the parameter from inverse modelling of one single CA fatigue test. An appropriate choice of $u$ was found to be 1.16 .

For the derivation of $G_{q}^{L M P S}$ and $G_{q}^{L H S}$ it is assumed that the stress at crack initiation (the initiation strength) and the equivalent ERRs leading to unstable crack growth are reached at the same time. In the $\left[0^{\circ} /-90^{\circ}\right]_{\mathrm{S}}$ laminate layup the cracks grew unstably across the width when the cracks initiated, meaning that $G_{q}^{L H S}$ represents an upper-bound value for this quantity. $G_{q}^{L M P S}$ cannot be measured as no off-axis cracks were initiated in the $\left[0 \%-40^{\circ} / 0^{\circ} / 40^{\circ}\right]_{s}$ laminate layup under static loading before specimen failure. Due to this, it is assumed that $G_{q}^{L M P S}$ can be computed based on the stress in the off-axis layer at specimen failure. It should be noted that this assumption only influences results for predictions for stress ratios at $R \neq 0.1$, because the normalisation was carried out for data derived for $R=0.1$. Identical S-N curves and Paris' Law relationships at this stress ratio are obtained regardless of the choice of $G_{q}^{L M P S}$.

\section{Model validation and identification of limitations}

Figure 8 to Figure 11 show the model predictions alongside measured crack density results for two different layups, namely the $\left[0^{\circ} /-90^{\circ}\right]_{S}$ laminate, and the results from the $\left[0 \%-60^{\circ} / 0^{\circ} / 60^{\circ}\right]_{S}$ laminate layup reported in [20]. The purpose of comparing with results obtained from the $\left[0^{\circ} /-90^{\circ}\right]_{s}$ is to show how the proposed methodology performs for the multiaxial stress state at which the crack evolution parameters were calibrated. The purpose of comparing with the crack density evolution for the $\left[0^{\circ} /-60^{\circ} / 0^{\circ} / 60^{\circ}\right]_{s}$ laminate is to demonstrate how the methodology performs for another multiaxial stress state for CA, VA block loading and C-T CA fatigue tests. The geometry and number of elements used in the simulations are given in Table 4, where reference is given to Figure 2 for the definition of the parameters quoted in the table.

\begin{tabular}{|c|c|c|c|c|}
\hline Layup & $\begin{array}{c}L_{v} \cdot W \\
{\left[\mathrm{~mm}^{2}\right]}\end{array}$ & $\begin{array}{c}L_{v} \\
{[\mathrm{~mm}]}\end{array}$ & $\begin{array}{c}n_{i} \\
\left(W / t_{k}\right)\end{array}$ & $\begin{array}{c}n_{j} \\
\left(n_{j}=r \cdot n_{e}\right)\end{array}$ \\
\hline$\left[0^{\circ} /-90^{\circ}\right]_{s}$ & 1550 & 25 & 57 & 342 \\
\hline$\left[0^{\circ} /-60^{\circ} / 0^{\circ} / 60^{\circ}\right]_{s}$ & 1550 & $\frac{25}{\sin (60)}=28.9$ & 50 & 300 \\
\hline
\end{tabular}

Table 4: RVE size and number of elements used in the off-axis crack density simulation.

Figure 8 shows the measured crack density evolution in the $\left[0^{\circ} /-90^{\circ}\right]_{S}$ laminate compared to the extended GLOB-LOC model simulations using both linear-linear and log-linear scalings. The purpose of the linear-linear scaling is to demonstrate that the predictions match very well in terms of apparent saturation value and the purpose of the loglinear scaling is to show the good agreement between the model and the experiment for the evolution rate. In fact 
Glud, J.A., Dulieu-Barton, J.M., Thomsen, O.T. and Overgaard, L.C.T., "A stochastic multiaxial fatigue model for off-axis cracking in FRP laminates", International Journal of Fatigue, 103, 2017, 576-590. https://doi.org/10.1016/j.ijfatigue.2017.06.012

good agreement is found for all load levels, except when $N_{x}=302[\mathrm{~N} / \mathrm{mm}]$. Here the model simulation over-predicts the crack density evolution significantly, and it also appears that the model predictions saturate at another value than observed in the experiment. However, at this load level the specimens had several zones with delaminations, which were not observed at the other load levels. The occurrence of delaminations is not accounted for in the model. This means that the stress responsible for off-axis crack evolution in the $90^{\circ}$ layer is lower than predicted by the model, hence the model over-prediction of the crack density.

The crack density evolution results for the $60^{\circ}$ layer in the $\left[0^{\circ} /-60^{\circ} / 0^{\circ} / 60^{\circ}\right]_{s}$ laminate is shown in Figure 9 . This laminate is subjected to a different multiaxial stress state than was used for deriving/calibrating the evolution parameters. The model predictions are in good agreement with the experimental results demonstrating that the extended GLOB-LOC model works well for multiaxial stress states.

Figure 10 shows the extended GLOB-LOC model predictions for VA block loading compared to the experimentally measured crack densities. The model predictions show a good agreement with experimental results, but over-predict the apparent saturation of the crack density. The reason for this slight discrepancy is likely to be related to the way the model predicts damage accumulation during initiation. It should be noted that no other experimental studies on damage accumulation for off-axis crack initiation have been published in the open literature, and consequently no general rule for the description of damage accumulation is widely accepted as was pointed out in [23]. Therefore, for this work it suffices to conclude that the extended GLOB-LOC model appears to be conservative for low-high VA block loading.

Figure 11 shows the model predictions as compared to the experimentally measured crack density evolution for compression-tension CA loading. The comparison presented should be considered as qualitative since the empirical normalisation principle adopted to model the load ratio influence has not been validated for compression-tension loading. However, the magnitude of the compressive load element is small for the conducted C-T tests on the $[0 \%$ $\left.60^{\circ} / 0^{\circ} / 60^{\circ}\right]_{s}$ laminate, and the damaging effect of the compressive load part is assumed to be negligible. From Figure 11 it is seen that the model accurately captures the trend in the experimental data, where the compression-tension test is more damaging than the CA test at $N_{x}^{\max }=563\left[\frac{\mathrm{N}}{\mathrm{mm}}\right]$ (see Figure 9), despite the fact that the C-T test attains a lower maximum stress during the fatigue cycles. However, the model over-predicts the crack density at saturation, which provides a conservative estimation.

Comparisons with crack density evolution in the $\left[0^{\circ} /-40^{\circ} / 0^{\circ} / 40^{\circ}\right]_{s}$ laminate were left out in this work because the model predictions and the measured crack density evolution do not agree well. The reason for the poor agreement is because the cracks did not predominantly initiate from one edge, and then grow to the other edge in the $[0 \%$ $\left.40^{\circ} / 0^{\circ} / 40^{\circ}\right]_{s}$ laminate layup. The parametrisation of cracks initiating from one edge followed by crack growth towards the other edge is too simplistic to model RVEs with more complicated crack fields as is the case for the $0 \%$ $\left.40^{\circ} / 0^{\circ} / 40^{\circ}\right]_{s}$ laminate layup. A comparison between typical crack patterns observed in the 3 different laminate layups obtained from the ACC approach is shown in Figure 12, where it is shown that the crack fields for the $\left[0^{\circ} /-90^{\circ}\right]_{s}$ and 
Glud, J.A., Dulieu-Barton, J.M., Thomsen, O.T. and Overgaard, L.C.T., "A stochastic multiaxial fatigue model for off-axis cracking in FRP laminates", International Journal of Fatigue, 103, 2017, 576-590. https://doi.org/10.1016/j.ijfatigue.2017.06.012

$\left[0^{\circ} /-60^{\circ} / 0^{\circ} / 60^{\circ}\right]_{s}$ layups consist of long continuous cracks, whereas the crack pattern observed in the $[0 \%$

$\left.40^{\circ} / 0^{\circ} / 40^{\circ}\right]_{s}$ laminate consists of several small cracks initiating at the both edges and in the centre of the specimen.

To model these more complicated crack fields, a model must consider a discretisation of the crack elements (Figure 2) along the $y$-axis as well. The consequence of implementing such a crack discretization approach would be a significant increase of the computational expense, and is a consideration for future research.

\section{Conclusions}

A multi-scale multiaxial fatigue model for off-axis crack density evolution has been presented. The proposed multiscale model extends the GLOB-LOC off-axis crack damage modelling framework with additional stress analysis tools and with a fatigue off-axis crack evolution module. The additional stress analysis tools include predictive analyses of the influence of crack face sliding interaction at high crack densities, and a method to predict the varying intralaminar stress field in cracked layers from the volume average quantities as obtained from the GLOB-LOC framework. The additional stress analysis tools have been validated against detailed FE analyses, and a good agreement between FE analysis results and the predictions of the developed stress analysis tools was found. This confirms the applicability of the developed approach for the detailed stress analysis, as well as the implementation of the GLOB-LOC model framework with the additional stress analysis tools. The off-axis fatigue crack evolution module employs and combines physically based multiaxial fatigue criteria with an aim to limit/reduce the need for experimental characterisation tests. Furthermore, empirical relations are adopted to account for the load ratio influence. A simplifying parametrisation of the crack evolution process suitable for the case where off-axis cracks will predominantly grow from one edge to the other edge has been proposed and used to study the predictive capabilities of the new model. Two different laminates made from NCF glass fibre fabric have been fatigue tested, and the observed damage evolutions obtained using automatic crack counting (ACC) to derive the evolution parameters required in the model. The model has shown to provide satisfactory and albeit slightly conservative results for the crack density evolution for constant amplitude (CA) loading for a $[0 / 90]_{s}$ laminate, which was one of the laminates used to calibrate the evolution parameters. Subsequently, the model predictions were then compared to measured crack density evolution data for a $[0 /-60 / 0 / 60]_{s}$ laminate, where the cracked plies were subjected to a different multiaxial stress state and different mixed mode crack propagation conditions than the stress state / mode mixity conditions for which the model parameters were calibrated. The model has been shown to predict the crack density evolution well for constant amplitude (CA), variable amplitude (VA) and compression-tension (C-T) loading cases, thus indicating that the proposed modelling approach is capable of accurately simulating the different damage mechanisms leading to off-axis crack propagation in composite laminates. However, the parametrisation of the crack density evolution suggested in this paper, limits the applicability to test specimens where the geometry facilitates cracks that predominantly grow from one edge until they meet the other edge, which is the case for the $[0 / 90]_{s}$ and $[0 /-60 / 0 / 60]_{s}$ laminate layups investigated. However, this parametrisation is too simple to predict the evolution for laminate layups where multiple cracks initiate away from the edges and coalescence plays an important role in the crack evolution process, as has also been demonstrated in this work. Future work on the modelling of off-axis crack density evolution should therefore 
Glud, J.A., Dulieu-Barton, J.M., Thomsen, O.T. and Overgaard, L.C.T., "A stochastic multiaxial fatigue model for off-axis cracking in FRP laminates", International Journal of Fatigue, 103, 2017, 576-590. https://doi.org/10.1016/j.ijfatigue.2017.06.012

include a more sophisticated parametrisation of the crack initiation and evolution process than has been used for the research presented in this paper.

\section{Acknowledgements}

The work presented was conducted as a part of a Ph.D. project at the Department of Mechanical and Manufacturing Engineering, Aalborg University, Denmark. A part of the research was carried out during a visit of the corresponding author at the University of Southampton, Faculty of Engineering and the Environment, Southampton, UK. The project has received sponsorship from Innovation Fund Denmark through the "Danish Centre for Composite Structures and Materials for Wind Turbines (DCCSM)". The support received is gratefully acknowledged.

\section{References}

[1] Jamison, Russell D. Characterization and analysis of damage mechanisms in tension-tension fatigue of graphite/epoxy laminates. vol. 1. ASTM International; 1984.

[2] Degrieck J, Van Paepegem W. Fatigue damage modeling of fibre-reinforced composite materials: Review. Appl Mech Rev 2001;54:279. doi:10.1115/1.1381395.

[3] Quaresimin M, Susmel L, Talreja R. Fatigue behaviour and life assessment of composite laminates under multiaxial loadings. Int J Fatigue 2010;32:2-16. doi:10.1016/j.ijfatigue.2009.02.012.

[4] Hwang W, Han KS. Fatigue of Composites--Fatigue Modulus Concept and Life Prediction. J Compos Mater 1986;20:154-65. doi:10.1177/002199838602000203.

[5] Hahn HT, Kim RY. Proof testing of composite materials. J Compos Mater 1975;9:297-311. doi:10.1177/002199837500900308.

[6] Talreja R. Multi-scale modeling in damage mechanics of composite materials. J Mater Sci 2006;41:6800-12. doi:10.1007/s10853-006-0210-9.

[7] Shokrieh MM, Lessard LB. Progressive fatigue damage modeling of composite materials, Part I: Modeling. J Compos Mater 2000;34:1056-80. doi:10.1177/002199830003401301.

[8] Eliopoulos EN, Philippidis TP. A progressive damage simulation algorithm for GFRP composites under cyclic loading. Part I: Material constitutive model. Compos Sci Technol 2011;71:742-9.

doi:10.1016/j.compscitech.2011.01.023.

[9] Sun XS, Haris A, Tan VBC, Tay TE, Narasimalu S, Della CN. A multi-axial fatigue model for fiber-reinforced composite laminates based on Puck's criterion. J Compos Mater 2012;46:449-69.

doi:10.1177/0021998311418701.

[10] Kennedy CR, Brádaigh CMÓ, Leen SB. A multiaxial fatigue damage model for fibre reinforced polymer composites. Compos Struct 2013;106:201-10. doi:10.1016/j.compstruct.2013.05.024.

[11] Quaresimin M, Carraro PA, Mikkelsen LP, Lucato N, Vivian L, Brøndsted P, et al. Damage evolution under cyclic multiaxial stress state: A comparative analysis between glass/epoxy laminates and tubes. Compos Part B Eng 2014;61:282-90. doi:10.1016/j.compositesb.2014.01.056.

[12] Quaresimin M, Carraro PA. Damage initiation and evolution in glass/epoxy tubes subjected to combined tension-torsion fatigue loading. Int J Fatigue 2014;63:25-35. doi:10.1016/j.ijfatigue.2014.01.002.

[13] Adden S, Horst P. Damage propagation in non-crimp fabrics under bi-axial static and fatigue loading. Compos Sci Technol 2006;66:626-33. doi:10.1016/j.compscitech.2005.07.034. 
Glud, J.A., Dulieu-Barton, J.M., Thomsen, O.T. and Overgaard, L.C.T., "A stochastic multiaxial fatigue model for off-axis cracking in FRP laminates", International Journal of Fatigue, 103, 2017, 576-590. https://doi.org/10.1016/j.ijfatigue.2017.06.012

[14] Wharmby AW, Ellyin F. Damage growth in constrained angle-ply laminates under cyclic loading. Compos Sci Technol 2002;62:1239-47. doi:10.1016/s0266-3538(02)00075-1.

[15] Carraro PA, Quaresimin M. A stiffness degradation model for cracked multidirectional laminates with cracks in multiple layers. Int J Solids Struct 2015;58:34-51. doi:10.1016/j.ijsolstr.2014.12.016.

[16] Vinogradov V, Hashin Z. Probabilistic energy based model for prediction of transverse cracking in cross-ply laminates. Int J Solids Struct 2005;42:365-92. doi:10.1016/j.ijsolstr.2004.06.043.

[17] Varna J. Modelling mechanical performance of damaged laminates. J Compos Mater 2013;47:2443-74. doi:10.1177/0021998312469241.

[18] Singh C V, Talreja R. Evolution of ply cracks in multidirectional composite laminates. Int J Solids Struct 2010;47:1338-49. doi:10.1016/j.ijsolstr.2010.01.016.

[19] Quaresimin M, Carraro PA. On the investigation of the biaxial fatigue behaviour of unidirectional composites. Compos Part B Eng 2013;54:200-8. doi:10.1016/j.compositesb.2013.05.014.

[20] Glud JA, Dulieu-Barton JM, Thomsen OT, Overgaard LCT. Fatigue damage evolution in GFRP laminates with constrained off-axis plies. Compos Part A Appl Sci Manuf 2017;95:359-69. doi:10.1016/j.compositesa.2017.02.005.

[21] Sun Z, Daniel IM, Luo JJ. Modeling of fatigue damage in a polymer matrix composite. Mater Sci Eng A 2003;361:302-11. doi:10.1016/S0921-5093(03)00556-2.

[22] Huang Y. Stochastic damage evolution under static and fatigue loading in composites with manufacturing defects. PhD dissertation. Texas A\&M University, 2012.

[23] Carraro PA. Multiaxial fatigue behaviour of composite materials: characterisation and modelling. PhD dissertation. University of Padova, 2014.

[24] Kahla H Ben, Varna J, Pupurs A. Microcracking in layers of composite laminates in cyclic loading with tensile transverse stress component in layers. 20th Int. Conf. Compos. Mater., 2015.

[25] Carraro PA, Maragoni L, Quaresimin M. Prediction of the crack density evolution in multidirectional laminates under fatigue loading. Compos Sci Technol 2017.

[26] Adam TJ, P. Horst. Cracking and delamination of cross- and angle ply gfrp bending specimens under very high cycle fatigue loading. 20th Int. Conf. Compos. Mater., 2015, p. 2104-4.

[27] Lundmark P, Varna J. Crack face sliding effect on stiffness of laminates with ply cracks. Compos Sci Technol 2006;66:1444-54. doi:10.1016/j.compscitech.2005.08.016.

[28] Lundmark P, Varna J. Constitutive relationships for laminates with ply cracks in in-plane loading. Int J Damage Mech 2005;14:235-59. doi:10.1177/1056789505050355.

[29] Lundmark P, Varna J. Stiffness reduction in laminates at high intralaminar crack density: effect of crack interaction n.d. doi:10.1177/1056789509351840.

[30] Quaresimin M, Carraro PA, Maragoni L. Influence of load ratio on the biaxial fatigue behaviour and damage evolution in glass/epoxy tubes under tension-torsion loading. Compos Part A Appl Sci Manuf 2015;78:294302. doi:10.1016/j.compositesa.2015.08.009.

[31] Hashin Z, Rotem A. A fatigue failure criterion for fiber reinforced materials. J Compos Mater 1973;7:448-64. doi:10.1177/002199837300700404.

[32] Kawai M, Yajima S, Hachinohe A, Takano Y. Off-Axis Fatigue Behavior of Unidirectional Carbon FiberReinforced Composites at Room and High Temperatures. J Compos Mater 2001;35:545-76. 
doi:10.1177/002199801772662073.

[33] Ogin SL, Smith PA, Beaumont PWR. A stress intensity factor approach to the fatigue growth of transverse ply cracks. Compos Sci Technol 1985;24:47-59. doi:10.1016/0266-3538(85)90060-0.

[34] Boniface L, Ogin SL. Application of the paris equation to the fatigue growth of transverse ply cracks. J Compos Mater 1989;23:735-54. doi:10.1177/002199838902300706.

[35] Carraro PA, Quaresimin M. A damage based model for crack initiation in unidirectional composites under multiaxial cyclic loading. Compos Sci Technol 2014;99:154-63. doi:10.1016/j.compscitech.2014.05.012.

[36] Sevenois RDB, Garoz D, Gilabert FA, Spronk SWF, Van Paepegem W. Microscale based prediction of matrix crack initiation in UD composite plies subjected to multiaxial fatigue for all stress ratios and load levels. Compos Sci Technol 2017;142:124-38. doi:10.1016/j.compscitech.2017.02.004.

[37] Glud JA, Carraro PA, Quaresimin M, Dulieu-Barton JM, Thomsen OT, Overgaard LCT. A physically based model for off-axis fatigue crack propagation in FRP composites. Compos Part A Appl Sci Manuf 2017:Under review.

[38] Quaresimin M, Carraro PA, Maragoni L. Early stage damage in off-axis plies under fatigue loading. Compos Sci Technol 2016;128:147-54. doi:10.1016/j.compscitech.2016.03.015.

[39] Kawai M, Suda H. Effects of Non-Negative Mean Stress on the Off-Axis Fatigue Behavior of Unidirectional Carbon/Epoxy Composites at Room Temperature. J Compos Mater 2004;38:833-54. doi:10.1177/0021998304042477.

[40] Glud JA, Dulieu-Barton JM, Thomsen OT, Overgaard LCT. Automated counting of off-axis tunnelling cracks using digital image processing. Compos Sci Technol 2016;125:80-9. doi:10.1016/j.compscitech.2016.01.019.

[41] Li C, Ellyin F, Wharmby A. On matrix crack saturation in composite laminates. Compos Part B Eng 2003;34:47380. doi:10.1016/S1359-8368(03)00020-9.

[42] CASTILLO E, FERNÁNDEZ-CANTELI A. A Unified Statistical Methodology for Modeling Fatigue Damage. First. Springer; 2009.

[43] Varna J, Krasnikovs A, Kumar RS, Talreja R. A synergistic damage mechanics approach to viscoelastic response of cracked cross-ply laminates. Int J Damage Mech 2004;13:301-34. doi:10.1177/1056789504042457.

[44] Nairn JA, Hu S, Bark JS. A critical evaluation of theories for predicting microcracking in composite laminates. J Mater Sci 1993;28:5099-111. doi:10.1007/BF00361186. 


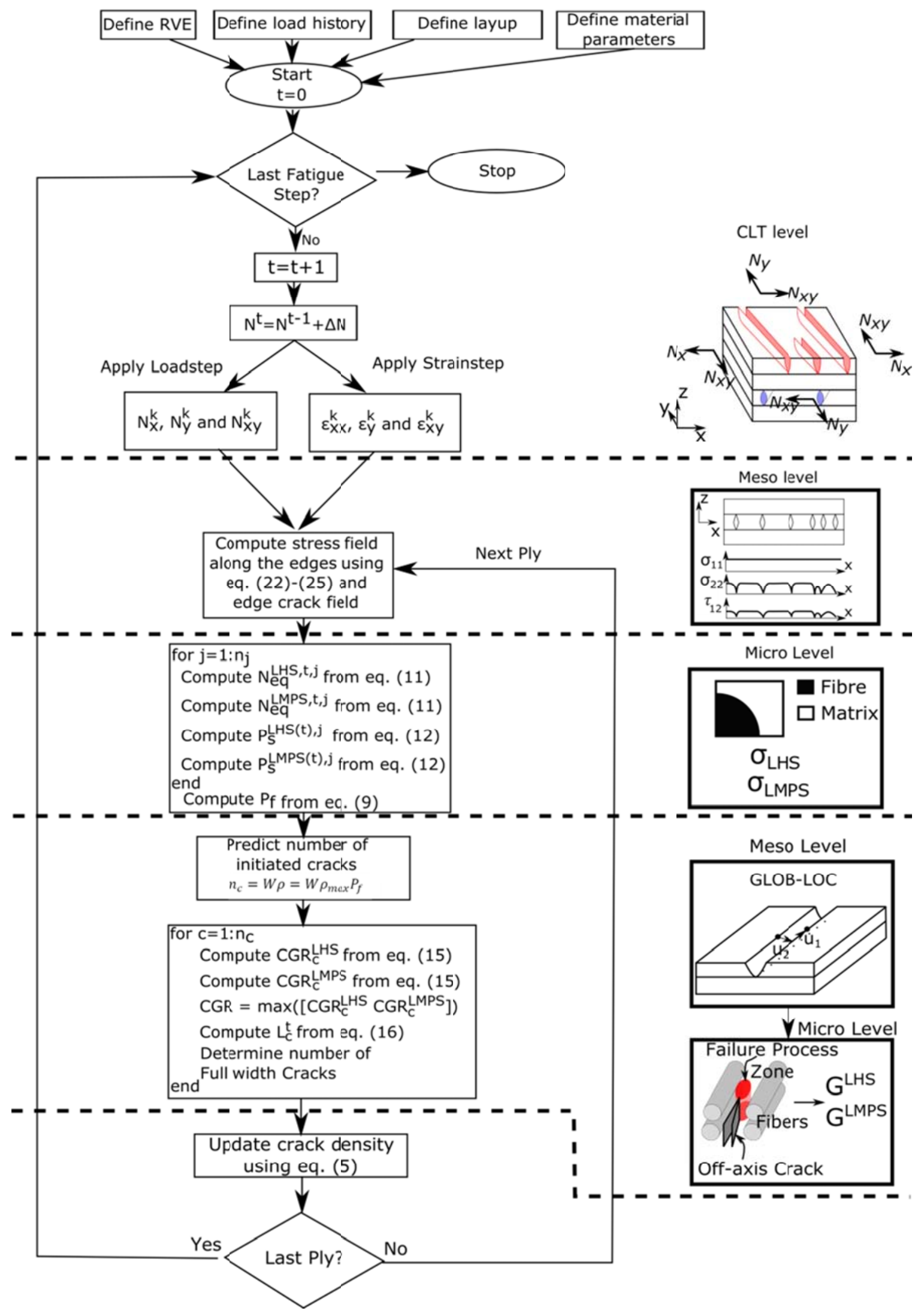

Figure 1: Flowchart for the crack density calculation, where the sketches on the right side illustrate the length scale at which the computations are carried out. 


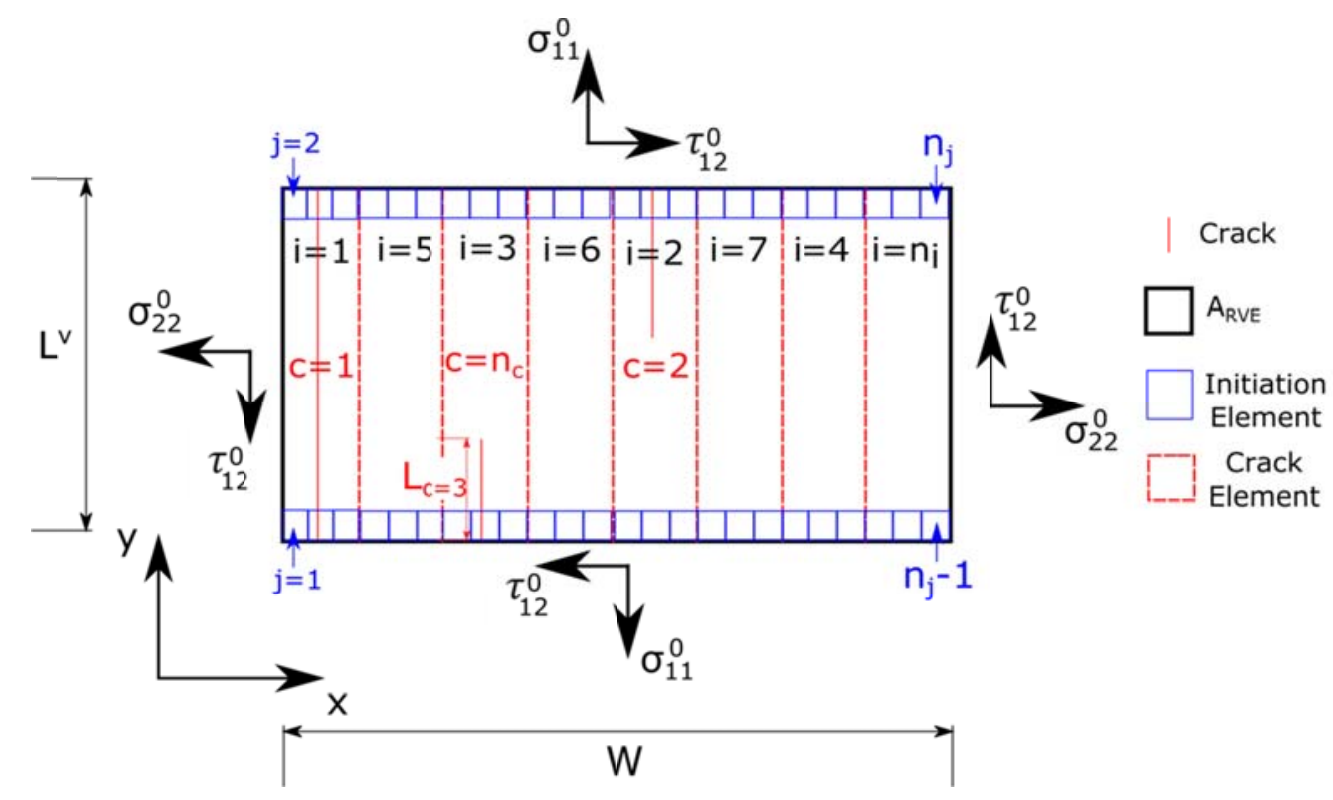

Figure 2: Representative volume for the crack evolution process model.
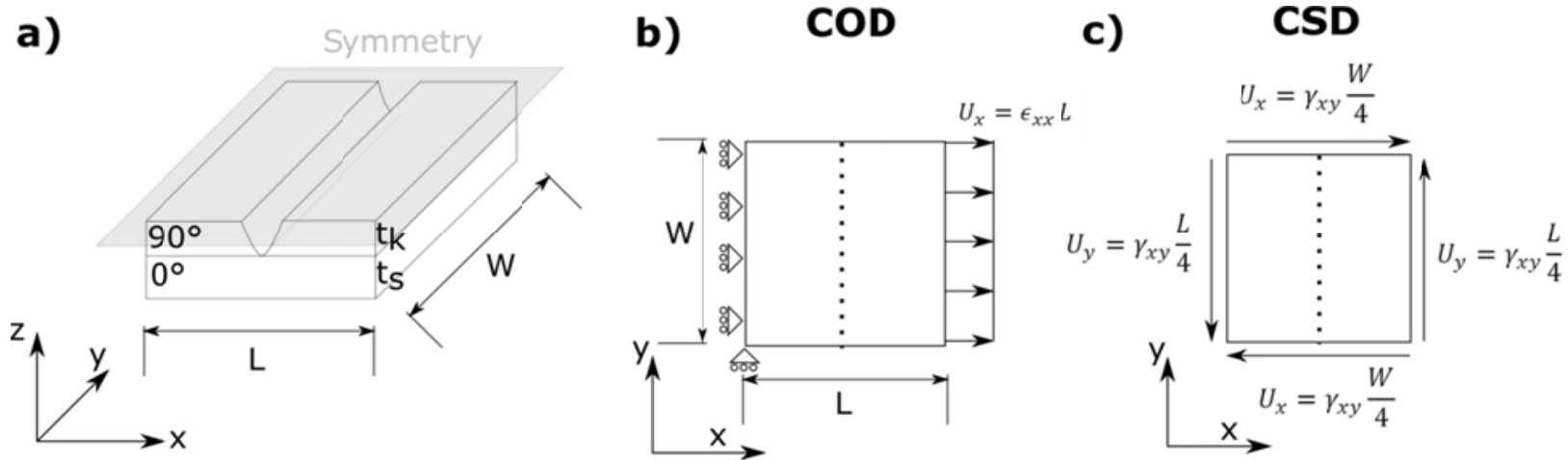

Figure 3: (a) FEA 3D unit-cell model, and B.C.'s for (b) COD and (c) CSD in teraction studies. 


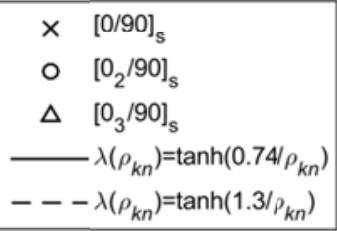

(a)

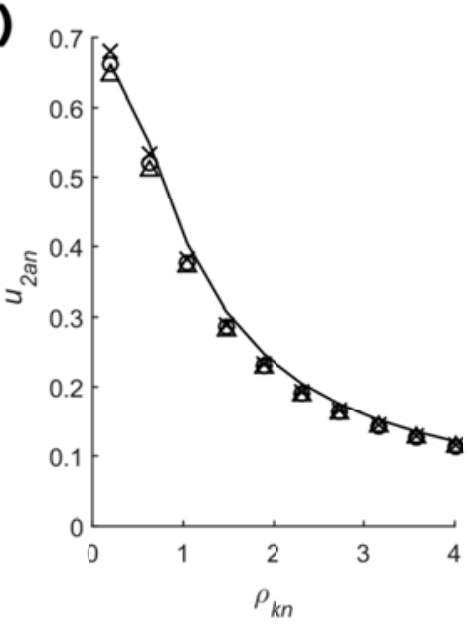

(b)

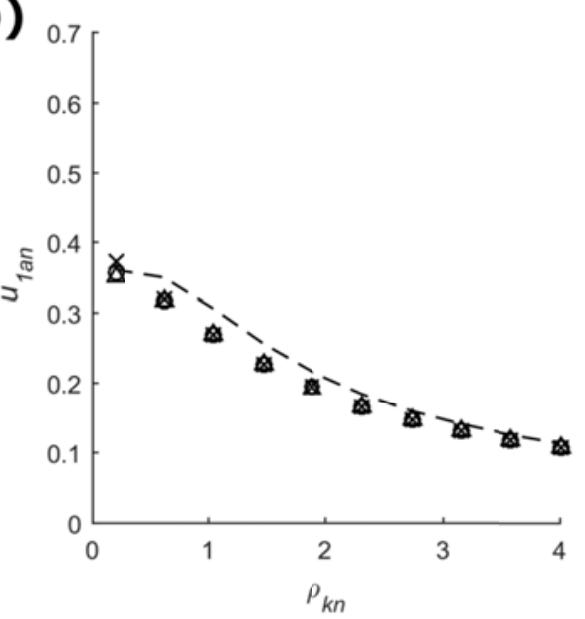

Figure 4: (a) Normalised COD, and (b) Normalised CSD for different constraining as function of normalised crack density.

(a)

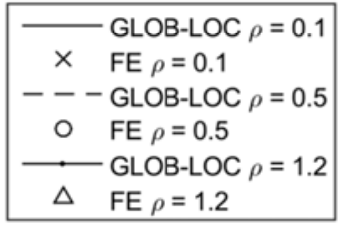

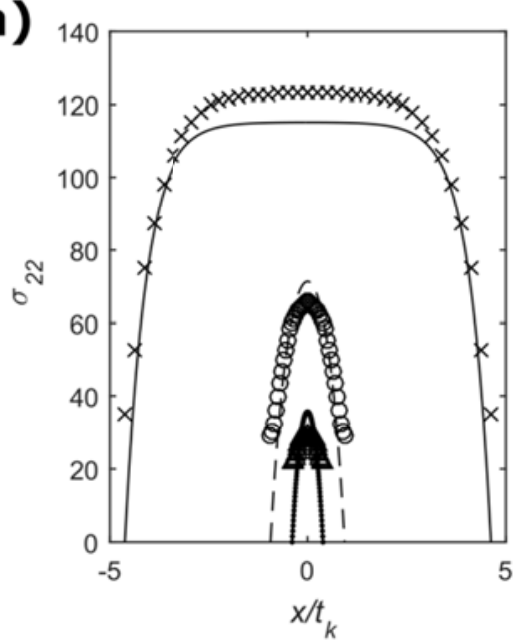

(b)

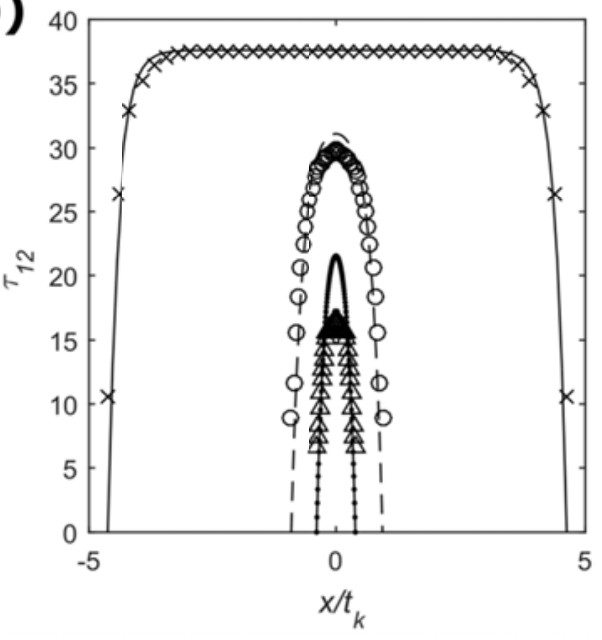

Figure 5: (a) Transverse normal stress field, and (b) Shear stress field between off-axis cracks for different crack densities for a [0/90]s layup and 1\% strain applied. 


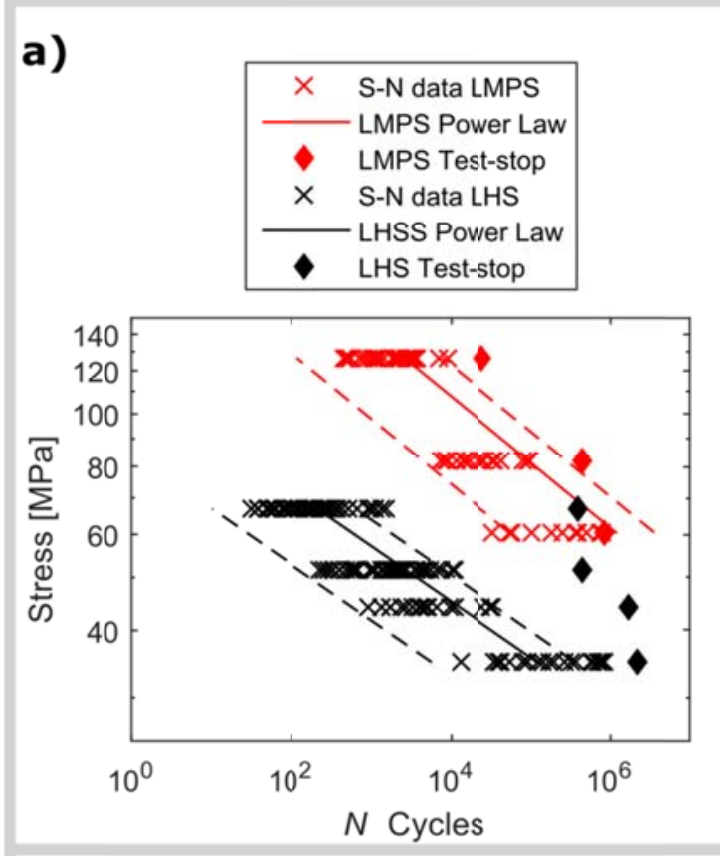

b) Failure Envelope $R=0.1, \sigma_{11}=0$
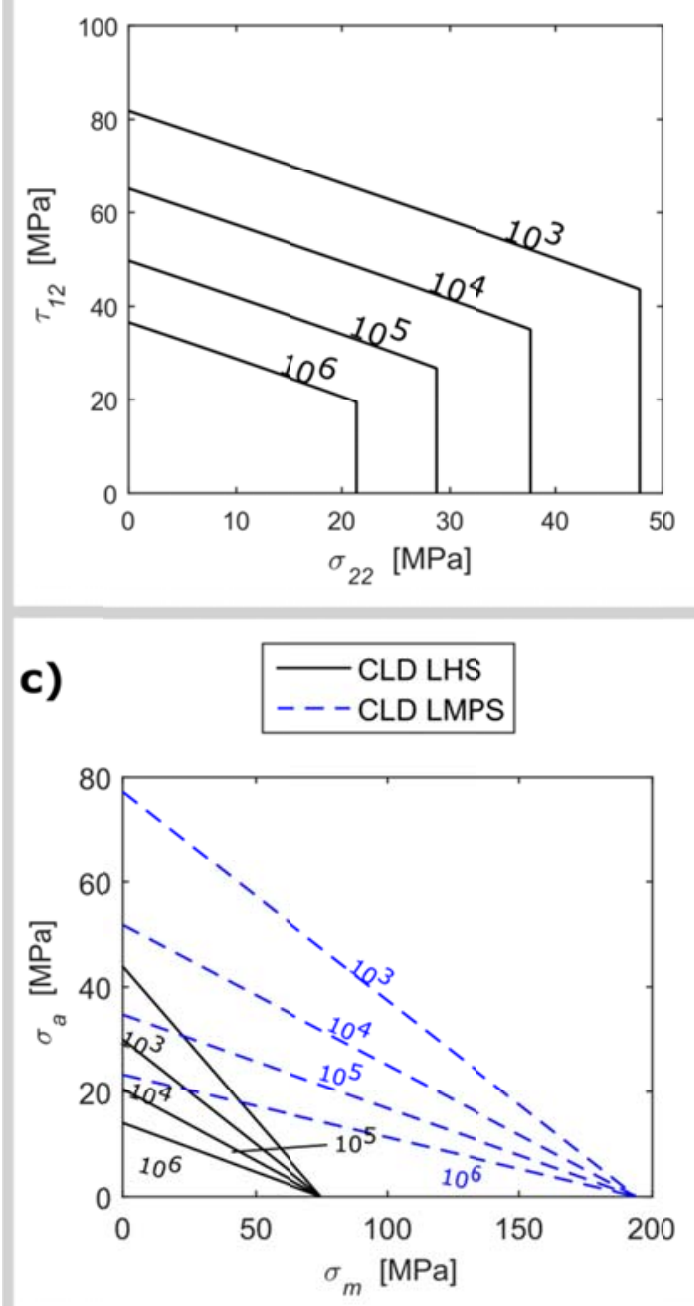

Figure 6: (a) S-N data points and fitted S-N relationships for non-interacting cracks. Test-stop refers to the instant where the laminates were not subjected to more laad cycles and were therefore removed from the test machine. (b) Multiaxial failure envelope and (c) Constant life diagrams for different number of cycles to crack initiation. 
a)
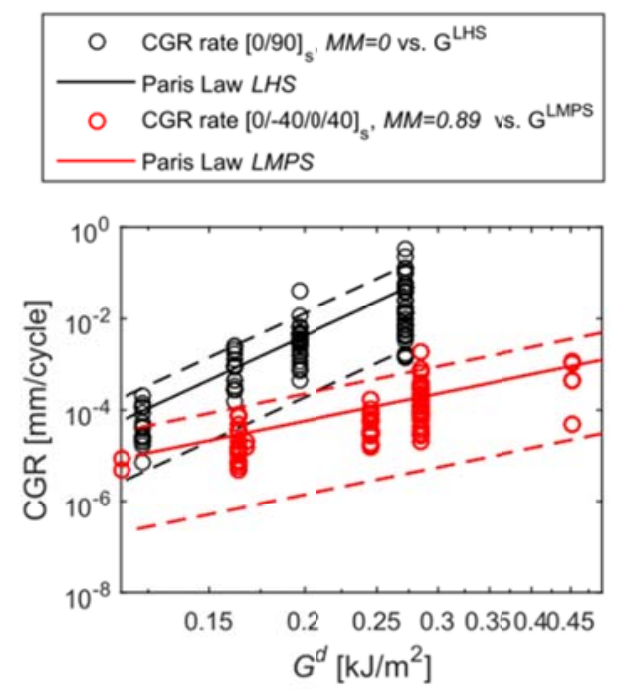

b)

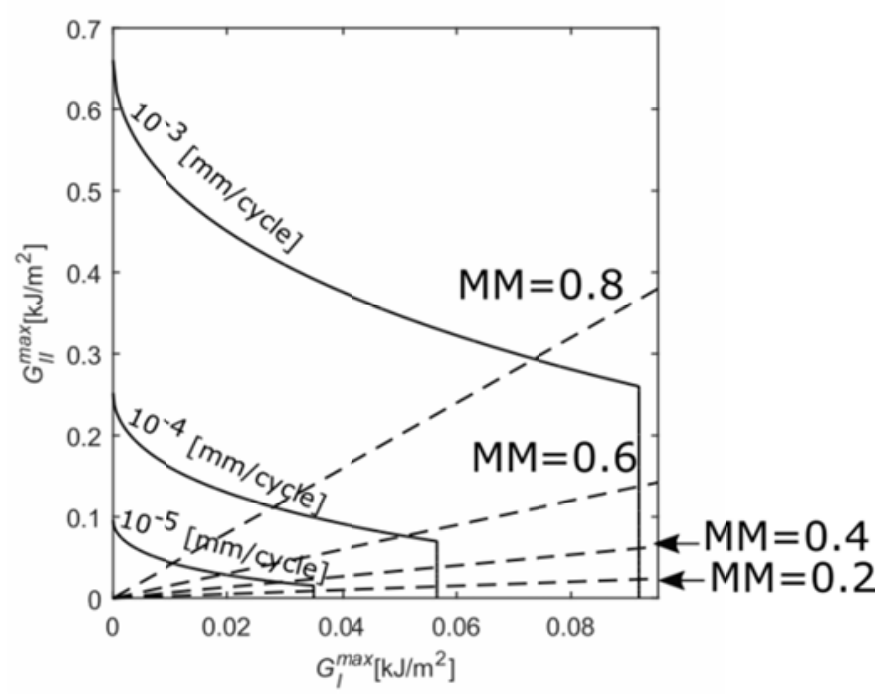

Figure 7: (a) Measured crack growth rates for each of the two propagation modes fitted with

Paris' law relationships, and (b) Constant CGR curves showing the mode-mixity where the propagation mode changes.

$[0 / 90]_{\mathrm{s}} N_{x}=302[\mathrm{~N} / \mathrm{mm}]$
$[0 / 90]_{\mathrm{s}} N_{x}=240[\mathrm{~N} / \mathrm{mm}]$
$[0 / 90]_{\mathrm{s}} N_{x}=203[\mathrm{~N} / \mathrm{mm}]$
$[0 / 90]_{\mathrm{s}} N_{x}=160[\mathrm{~N} / \mathrm{mm}]$

a)

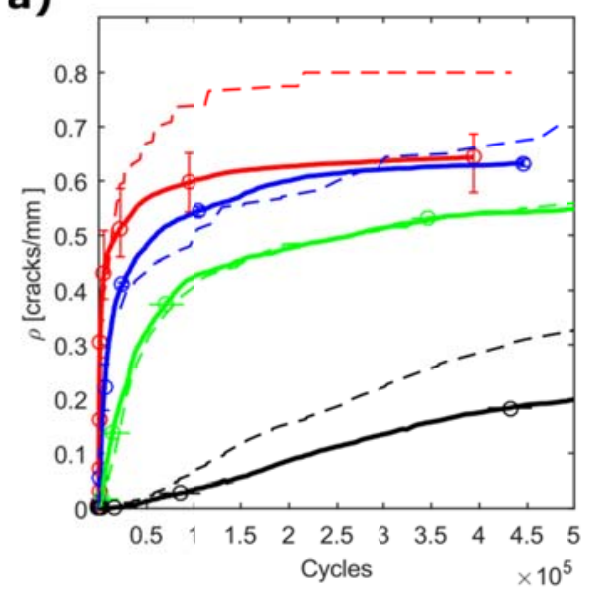

\section{b)}

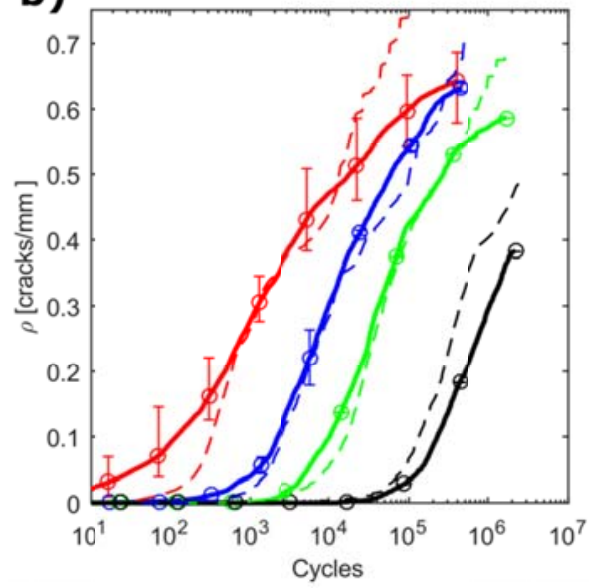

Figure 8: Crack density evolution for the $90^{\circ}$ layer (denoted with boldface notation in the laminate layup in the figure legend) in the [0/90] s laminate subjected to CA fatigue loading at a load ratio of $R=0.1$. (a) Linear $x$ axis scaling, and (b) Logarithmic $x$ axis scaling. Solid lines represent experimentally measured crack density and dashed lines are model predictions. 


$[0 /-60 / 0 / 60]_{\mathrm{s}} N_{x}=721[\mathrm{~N} / \mathrm{mm}]$
$[0 /-60 / 0 / 60]_{\mathrm{s}} N_{x}=563[\mathrm{~N} / \mathrm{mm}]$
$[0 /-60 / 0 / 60]_{\mathrm{s}} N_{x}=447[\mathrm{~N} / \mathrm{mm}]$

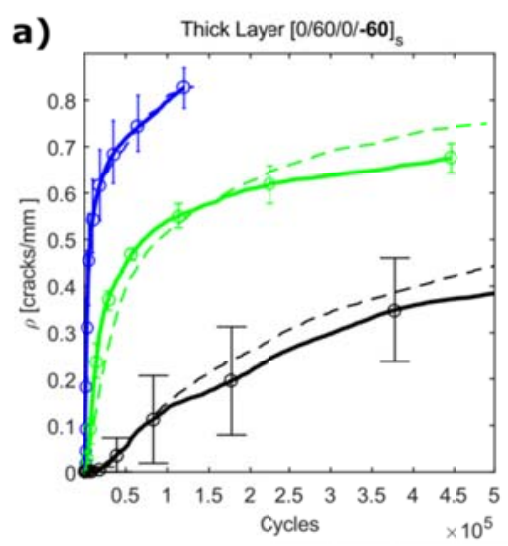

b)

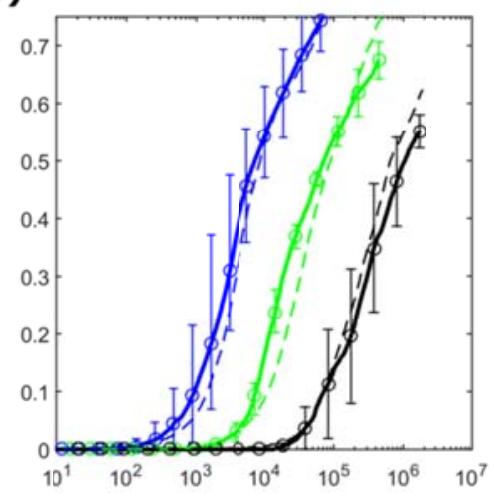

Figure 9: Crack density results for the $60^{\circ}$ (denoted with boldface notation in the laminate layup in the figure legend) layer in the [0/-60/0/60]s laminate subjected to CA fatigue loading at a load ratio

of $R=0.1$. (a) Linear $x$ axis scaling, and (b) Logarithmic $x$ axis scaling. Sollid lines represent experimentally measured crack density and dashed lines are model predictions.

- VA loading $[0 /-60 / 0 / 60]_{S}$

1st block: $N_{X}=563[\mathrm{~N} / \mathrm{mm}]$

2nd block: $N_{X}=721[\mathrm{~N} / \mathrm{mm}]$
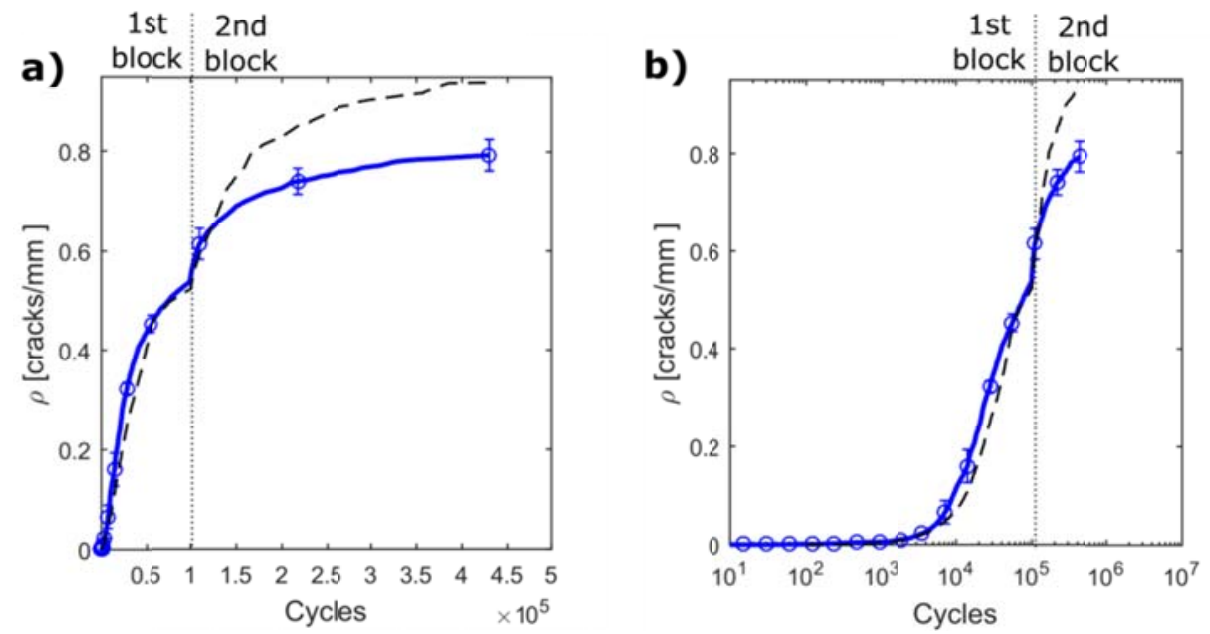

Figure 10: Crack density results for the $60^{\circ}$ layer (denoted with boldface notation in the laminate layup in the figure legend) in the [0/-60/0/60]s laminate subjected to VA black loading at a load ratio of $R=0.1$. (a) Linear $x$ axis scaling, and (b) Logarithmic $x$ axis scaling. Solid lines represent experimentally measured crack density and dashed lines are model predictions. 


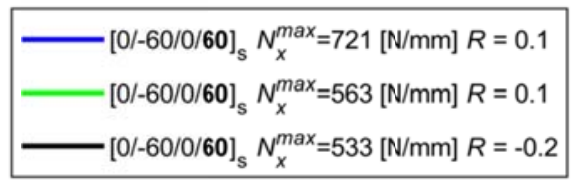

a)

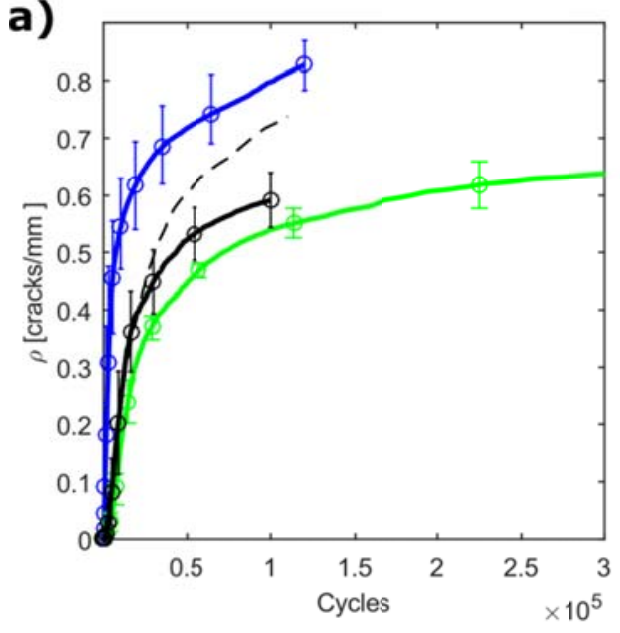

b)

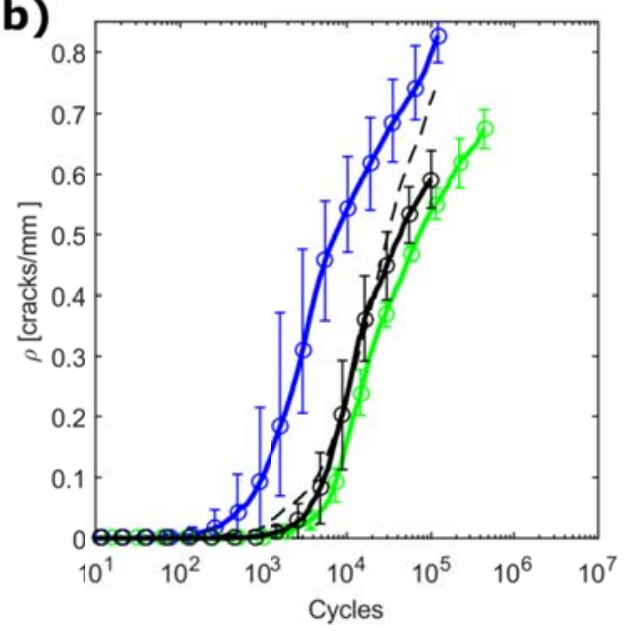

Figure 11: Crack density results for the $60^{\circ}$ layer (denoted with boldface notation in the laminate layup in the figure legend) in the [0/-60/0/60] laminate subjected to C-T fatigue loading. (a) Linear $x$ axis scaling, and (b) Logarithmic $x$ axis scaling. Solid lines represent experimentally measured crack density and dashed lines are model predictions.

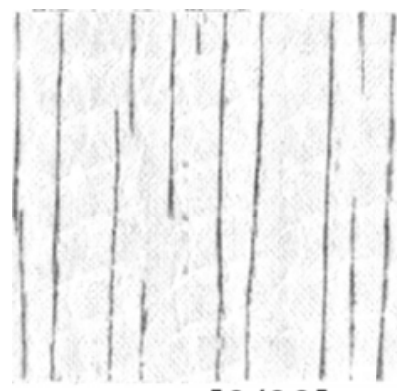

$[0 / 90]_{s}$

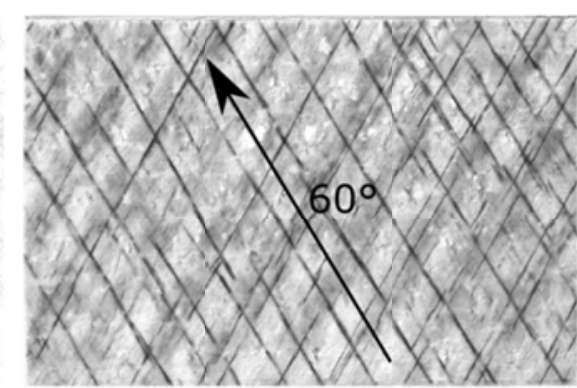

$[0 /-60 / 0 / 60]_{S}$

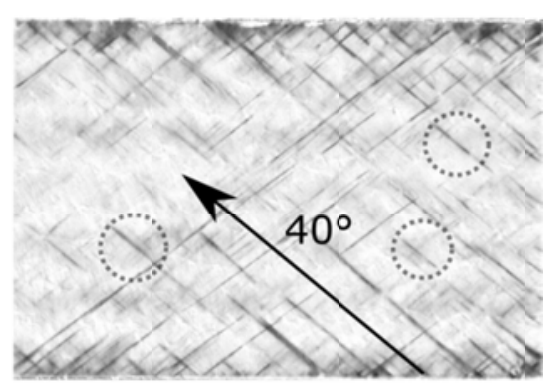

$[0 /-40 / 0 / 40]_{S}$

Figure 12: Crack fields in the three different laminates. 